\title{
Formulation of cellulose using groundnut husk as an environment-friendly fluid loss retarder additive and rheological modifier comparable to PAC for WBM
}

\author{
Atul Kumar Patidar ${ }^{1}$ D $\cdot$ Anjali Sharma ${ }^{1} \cdot$ Dev Joshi $^{1}$
}

Received: 9 June 2020 / Accepted: 12 August 2020 / Published online: 19 August 2020

(c) The Author(s) 2020

\begin{abstract}
The hydrocarbon extraction and exploitation using state-of-the-art modern drilling technologies urge the use of biodegradable, environment-friendly drilling fluid and drilling fluid additives to protect the environment and humanity. As more environmental laws are enacted and new safety rules implemented to oust the usage of toxic chemicals as fluid additives, it becomes inevitable that we re-evaluate our choice of drilling fluid additives. Drilling fluids and its additives play a crucial role in drilling operations as well as project costing; hence, it is needed that we develop cost-effective environment-friendly drilling fluid additives that meet the requirements for smooth functioning in geologically complex scenarios as well as have a minimal ecological impact. The current research work demonstrates key outcomes of investigations carried out on the formulation of a sustainable drilling fluid system, where groundnut husk is used as a fluid loss additive and a rheological modifier having no toxicity and high biodegradability. Cellulose was generated from groundnut husk at two varying particle sizes using mesh analysis, which was then compared with the commercially available PAC at different concentrations to validate its properties as a comparable fluid loss retarder additive as well as a rheological modifier. In the present work, various controlling characteristics of proposed groundnut husk additive are discussed, where comparison at different concentrations with a commercially available additive, PAC, is also validated. The API filtration losses demonstrated by the (63-74) $\mu \mathrm{m}$ and the (250-297) $\mu \mathrm{m}$ proposed additive showed a decrease of $91.88 \%$ and $82.31 \%$, respectively, from the base mud at $4 \%$ concentration. The proposed husk additives acted as a filtrate retarder additive without much deviation from base rheology and with considerably higher $\mathrm{pH}$ than the base mud. This investigation indicates that the proposed fluid loss additive and rheological modifier can minimize the environmental hazards and have proved to be a cost-effective eco-friendly alternative in this challenging phase of the hydrocarbon exploration industry.
\end{abstract}

Keywords Biodegradable $\cdot$ Cellulose $\cdot$ Fluid loss additive $\cdot$ Groundnut husk $\cdot$ Rheological modifier

$\begin{array}{ll}\text { Abbreviations } \\ \text { PAC } & \text { Polyanionic cellulose } \\ \text { PV } & \text { Plastic viscosity } \\ \text { AV } & \text { Apparent viscosity } \\ \text { YP } & \text { Yield point } \\ \text { API } & \text { American petroleum institute } \\ \text { LPLT } & \text { Low pressure low temperature } \\ \text { ECD } & \text { Equivalent circulation density }\end{array}$

Atul Kumar Patidar

apatidar@ddn.upes.ac.in

1 Department of Petroleum Engineering and Earth Sciences, University of Petroleum and Energy Studies (UPES), Dehradun, India

\section{Introduction}

The utilization of drilling fluids is the requisite of rotary drilling processes. Drilling fluids are designed to assist drilling by minimizing reservoir damage and increasing the productivity of the pay zone (Hossain and Wajheeuddin 2016; Shettigar et al. 2018). In earlier days, the drilling fluids comprised only of basic clay and water and thus had minimum environmental effects. However, as the drilling conditions became more challenging, many problems started to arise with the basic drilling fluid properties. Therefore, complex chemicals or additives need to be added to prepare the base mud to meet the best of its functions (Elkatatny 2019). Various useful prerequisites of drilling fluid such as appropriate mud rheology, density, mud activity, fluid loss control are met using different formulations, various polymers, and

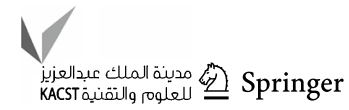


chemicals that are added as additives. Recently, the use of nanoparticles is widely accepted for the improvement in drilling fluid properties (Saboori et al. 2018). Today, the choice of drilling fluids and their additives has become complex and tedious considering both the technical and environmental factors (Amanullah et al. 1997; Caenn et al. 2016). Various environmental protection agencies and organizations have raised their concerns to protect the ecological system from hazardous drilling activities. The geologically complex deep wells are prone to drilling risk and associated environmental hazards, which are presently overseen by utilizing an oil-based drilling fluid framework or high-performance water-based drilling fluid framework. The much more detrimental effects of oil-based muds on the environment dictate the use of water-based muds (WBM) for increasing drilling fluid applications. Although the WBM is desirable in oil \& gas drilling because of its minimal environmental impact, it has inferior properties to support deep drilling than oil-based muds in terms of performance and thermal stability. Due to strict limitations in HSE policies/norms, the environmental safety has become a prime consideration for oil \& gas industry and researchers are paying more attention to prepare an economically friendly biodegradable drilling fluid composition for the protection of ecological system (Shuixiang et al. 2011; Hossain and Wajheeuddin 2016; Akinade et al. 2018).

Recent technological advancement has led to the development of novel environment-friendly drilling fluid solutions. The advancement in the direction of sustainable and economically viable drilling fluid systems has been constrained by factors such as complicated chemical synthesis technology, absence of crude material, and high cost (Li et al. 2014). Synthetic and mineral oils are commonly used in oil-based drilling fluid systems. However, there are multiple disadvantages associated with these types of oils. Fundamentally, these oils (synthetic/mineral) have toxic, non-renewable, and non-biodegradable properties. On the other end, they do not accomplish to defined HSE norms and many a time are prompting toward the incredible expense of waste treatment processes. Earlier, little consideration was given to monitoring the ecological conditions at less environmentally sensitive regions for hydrocarbon drilling operations. Now, this delay brought the realization of negative environmental impact from drilling fluid additives such as chemicals, polymers, saltwater, and oil-based fluids (Amanullash 2007). The non-biodegradable additives used in controlling drilling fluid properties cause harm to the environment and personal safety. To control the risk and uncertainties in oil \& gas drilling operations and to minimize the drilling hazards, the environment-friendly drilling fluid additive, which adheres to the HSE norms and minimize the waste disposal treatment cost, is the prime demand of the hydrocarbon industry (Al-Hameedi et al. 2020a). However, the health exposure standard of the workers has not always been given the mandatory attention. This is because the occupational hygiene exposures are often not adequately assessed to determine the actual risk to workers. Their direct exposure to drilling fluids is at a constant health risk like dizziness, headaches, nausea, dermatitis, and even cancer (Al-Hameedi et al. 2020a). The preparation of the Exposure Control Plan (ECP) is the most effective and foremost step toward reducing/eliminating the risk of direct exposure with the hazardous source. The method of control is to eliminate or substitute hazardous material with an eco-friendly and safe alternative by enforcement of Material Safety Data Sheets (MSDS) or a safer process. However, the implementation of a safer process often leads to an overall increase in operation cost. The total elimination of the environmental impact of mud and mud additives by selecting or developing highly pure and most environment-friendly additives with readily biodegradable characteristics is very important for mud and mud waste disposal in an offshore or onshore environment, especially in areas having highly sensitive species (Agwu and Akpabio 2018; Al-Hameedi et al. 2020a). Therefore, it becomes the utmost necessity to replace the existing synthetic and mineral oil-based drilling fluid additives with natural substitutes, while at the same time implementing proper engineering and administrative controls to ensuring the provision of personal protective equipment. Numerous factors need to be considered for choosing a suitable drilling fluid formulation. A drilling fluid formulation offers a complex array of interrelated properties (Khamehchi et al. 2016; Al-Hameedi et al. 2020b). Five basic properties are usually defined by the well program and monitored during drilling. These properties are viscosity, density, filter cake or filtration of water loss, solid content, and quality of water make up. Once the properties and their parameters are determined, drilling fluid rheology can be controlled and adjusted accordingly (Fattah and Lashin 2016; Hossain and Wajheeuddin 2016).

The systematic review of the best practices adopted by the drilling industry has given an idea to develop an ecofriendly fluid loss additive using the cellulose extracted from groundnut husk. The current research work demonstrates the process of preparation of cellulose derivative additive from groundnut husk with controlled rheological properties, which is a bio-compatible, sustainable, and cost-effective alternative to hazardous chemically originated drilling fluids. The laboratory testing of the working efficiency of the proposed additive is carried out, and comparative data analysis is presented in this paper. The comparative analysis shown by (Okon et al. 2020) using dried rice husk, suggests that his proposed mud cake will proficiently prevent differential pipe sticking and is an effective alternative to toxic chemical-based compositions. He has blended and sieved the base material using $125-\mu \mathrm{m}$ sieve to obtain desired particles size, whereas we have taken a range of particles, i.e., 
(63-74) $\mu \mathrm{m}$ and (250-297) $\mu \mathrm{m}$ to prepare an additive with a non-uniform gradation of particle sizes and distinctly compared its efficiency at different concentrations. Therefore, our proposed additive with a range of particles will provide efficient bridging and plugging as compared to using a single sized particle, where the fluid can escape through the micropores left around the edges/contacts of the uniform particles. (Cline et al. 1989) states that an excess emulsifier is used to ensure that the solids in an oil mud remain oilwet. But, if the solids were initially wet with water during the preparation or if the oil-based mud becomes inverted (water continuous), then the water-wet solids clump together and become difficult to revert to oil-wet. If this occurs, the mud solids stick together tenaciously and the mud system may not remain inhibitive to the drilled formation. Also, most of the oil-wet additives are liable to invade into formations along the fractures and may inevitably have negative impacts on the behaviors of reservoir stress sensitivity (Cline et al. 1989; Marques et al. 2019; Elochukwu and Sia 2019). Hence, it is proposed to use cost-effective, high-performance water-based drilling fluid additives. In the current research work, we have demonstrated a methodology to formulate the cellulose using groundnut husk as an environment-friendly fluid loss retarder additive and rheological modifier, which can be comparable to polyanionic cellulose (PAC) for waterbased drilling muds (WBM). The physical model of filter cake/mud cake is prepared, and the data generated in the laboratory are thoroughly analyzed, and the essential properties of drilling fluid are compared with available traditional alternatives. The processed cellulose from groundnut husk is analyzed in view to give better fluid loss reducing properties in low concentrations, at an economical price and environmentally friendly manner.

\section{Cellulose generation from groundnut husk}

The current research work demonstrates the process of formation and data analysis of a sustainable drilling fluid system, where biodegradable groundnut husk is used as a fluid loss additive and rheological modifier. The cellulose processed from groundnut husk is tested as an alternative for the current practice of using polyanionic cellulose in the drilling fluid formulation. A comparative analysis is made with a standard drilling fluid at different concentrations with the proposed additive to validate the results based on different parameters such as cost efficiency, good API filtration rate, and environmental friendliness. In the petroleum industry, the particle size analyzer has been extensively used to evaluate sedimentary grain size distribution and various other analyses by geologists. One of the major parameters that need to be considered for the determination of fluid loss properties is the particle size distribution in the drilling fluid
(Alsabagh et al. 2015). A drilling fluid having particle sizes up to the requisite maximum size will be able to effectively bridge the formation by the development of a filter cake or a mud cake. As the concentration of these bridging particles is increased, this formation of filter cake occurs faster as the permeability of the formation around the wellbore is substantially reduced by either clay swelling, particle blocking, or particle plugging. The filter cake thus formed should be thin, impermeable, and dense (Amanullah et al. 1997; Bjorlykke 2010).

\section{Methodology}

Direct exposure of human contact with drilling fluids can be hazardous, as some drilling fluid formulations may emit noxious or unsafe fumes that may reach levels that surpass the maximum recommended short-term or long-term safe exposure limits. Particularly for oil-based muds, some shale inhibitors and corrosion inhibitors tend to produce ammonia or other lethal as well as volatile amines, particularly in hot areas on a rig (Hossain and Wajheeuddin 2016). The extraction and exploitation of hydrocarbons in today's era urge the use of biodegradable, environment-friendly additives that prove to be at par with the current commercial additives in terms of availability, working proficiency, and cost-effectiveness. Drilling muds with less environmental impact are highly desired over conventional diesel-based mud systems, especially in light of the emerging strict environmental laws (Akinade et al. 2018; Kumar et al. 2020). The particle size and its concentration are the two crucial parameters, which determine the effectiveness of the industrial-grade ecofriendly drilling fluid additive. The determination of particle size was based on two different objectives.

- The first objective was to test the decreasing permeability of the filter cake with the mean particle diameter. To test this hypothesis, two different particle sizes were selected which ranges from 63 to $297 \mu \mathrm{m}$ size. The sample size having 63-74 $\mu \mathrm{m}$ particle size was in range with the mean particle diameter of PAC, and the other one was greater than the mean particle diameter.

- The second objective was to determine if the permeability decreases with increasing width or gradation of the particle size range. This was done to consequentially determine the degree of closeness of the size of the proposed additive to the range of PAC particles that achieved the least volume of fluid loss and hence the optimum size range. To examine if the uniform gradation of particles is of equal importance, the size distribution of particles was kept linear but not close to the range of the PAC additive. Hence, the second sample was prepared with the $250-297 \mu \mathrm{m}$ size.

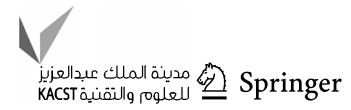


As per (Geng et al. 2014), the proper sizing of the additive concerning the pore size distribution is essential for developing a drilling fluid with effective sealing ability. To determine the most efficient particle concentration, the drilling fluid was tested at four different concentrations, i.e., at $1 \%, 2 \%, 3 \%$, and $4 \%$, for each of the additive. The drilling fluids' properties are continuously tested at the well site, and its composition is adjusted according to the requirement of drilling operations. These field tests are standardized according to the American Petroleum Institute Recommended Practices (API RP) 13 B-1, for water-based drilling fluids (Kekpugile and Godwin Jacob 2014; Fatihah Majid et al. 2019). These typically include testing for drilling fluid density, viscosity, rheology, gel strength, API filtration loss, pH (Chilingarian et al. 2007; Kosynkin et al. 2012; Huang et al. 2016). The physical model of filter cake/mud cake is critically evaluated in the laboratory, and the following properties are tested and compared with the available traditional alternatives.

- Filtration loss: The formulated samples were tested for filtration loss in a low pressure, low temperature (LPLT) Fann filter press. The fluid is subjected to static filtration at $100 \mathrm{~Pa}$, and the fluid loss readings were taken at 10 , 20, and $30 \mathrm{~min}$.

- Rheology: Automatic viscometer was used to measure stress at speeds of $\theta 600, \theta 300, \theta 200, \theta 100, \theta 6, \theta 3$. The rheology of the drilling fluid was then calculated. The Fann viscometer, a form of automatic viscometer, enables the variation in shearing stress with shear rate. The assembly is lowered to a prescribed mark in a cup filled with mud, and the outer cylinder is rotated at a constant speed. The viscous drag of the mud turns the suspended bob until it is balanced by the torque in the string. The deflection of the bob is then read from the calibrated dial, which provides the shear stress at the surface of the bob.

- Gel strength: The fluid was subjected to a speed of $\theta 600$ for a minute, and then, the maximum deflection at $\theta 3$ was taken as Gel0. The viscometer was then stopped for $10 \mathrm{~min}$, and the maximum deflection at $\theta 3$ was taken as Gel10.

- $p H$ : The $\mathrm{pH}$ was tested using a standardized $\mathrm{pH}$ meter. For calibration, the $\mathrm{pH}$ of distilled water was tested first to be 7.0.

- Density: The density of the drilling fluid was measured using a mud balance. The procedure is to fill the cup with mud, put on the lid, wipe off excess of mud from the lid, move the rider along the arm till a balance is obtained, and read the density at the side of the rider toward the knife edge. For accuracy of the mud balance and to minimize any measurement uncertainty, the mud balance was calibrated first with fresh water; the measurement reading was $1 \mathrm{~g} / \mathrm{cc}$ or $8.33 \mathrm{lbs} / \mathrm{gal}$.
The methodology, instrument used, and other properties adopted in the current research work are shown as a working flowchart in Fig. 1. The laboratory analysis work was divided into three different stages. At Stage 1, the systematic extraction of cellulose from the groundnut husk was done. At Stage 2, the particle size distribution using mesh analysis was carried out at two varying particle sizes. At the final Stage 3, the desired composition of drilling fluid was prepared and the laboratory analysis data were recorded systematically. The testing compared with the commercially available PAC at different concentrations was also done during the data analysis and interpretation. The stage-wise details of the experiments are given below.

Stage 1: Cellulose extraction from groundnut husk: The good quality groundnut samples were procured from the open market, seeds were removed, and only the husk was used for cellulose extraction. Theoretically, the groundnut husk contains approximately $38.3 \%$ cellulose and $18.7 \%$ hemicellulose. The groundnut husk was thoroughly washed and left to dry. The groundnut is dried to attain the perfect texture for the additive. The groundnut husk is sensitive to extractive conditions. Strong alkali conditions and/or heating of the husk above $80^{\circ} \mathrm{C}$ could result in the disintegration of the husk and the dissolution of the cellulose into the solution not suitable for high-value fibrous applications (Kekpugile and Godwin Jacob 2014). The washed and dried husk was dipped into a $0.5 \mathrm{~N}$ sodium hydroxide solution with a solution to the husk ratio of 10:1 at room temperature overnight. The solution along with husk was then heated to $80{ }^{\circ} \mathrm{C}$ for $30 \mathrm{~min}$ in a hot air oven to vaporize the volatile impurities. The extracted components were drained, and fibers formed were thoroughly washed in warm water and then in cold water. This is done in order to remove any impurities and gently bring the husk to room temperature. After that, the sample is neutralized in dilute acetic acid solution to remove any remaining alkali content and then dried in sunlight for a week. Finally, it is oven-dried to remove remaining moistures and fine powder is prepared using a stone grinder (Fig. 2).

Stage 2: Particle size distribution using mesh analysis: After grinding the dry husk, the desired particle size was attained by using mesh analysis. To manage the desired size of the husk, ground fibers were passed through various meshes. To separate the desired $297-\mu \mathrm{m}$ fibers from the rest, the sample was passed through a sieve of mesh size 50. The fibers which passed through this sieve were all less than $297 \mu \mathrm{m}$ and were again made to pass through a sieve of a mesh size corresponding to $250 \mu \mathrm{m}$ which retained particles larger than $250 \mu \mathrm{m}$ (Fig. 3). Hence, the desired particle size range of $250-297 \mu \mathrm{m}$ was obtained by a mesh analysis of $-50+60$. Similarly, to separate the desired 74- $\mu \mathrm{m}$ fibers from the rest, the sample was passed through a sieve of mesh size 200. The fibers passed through this 


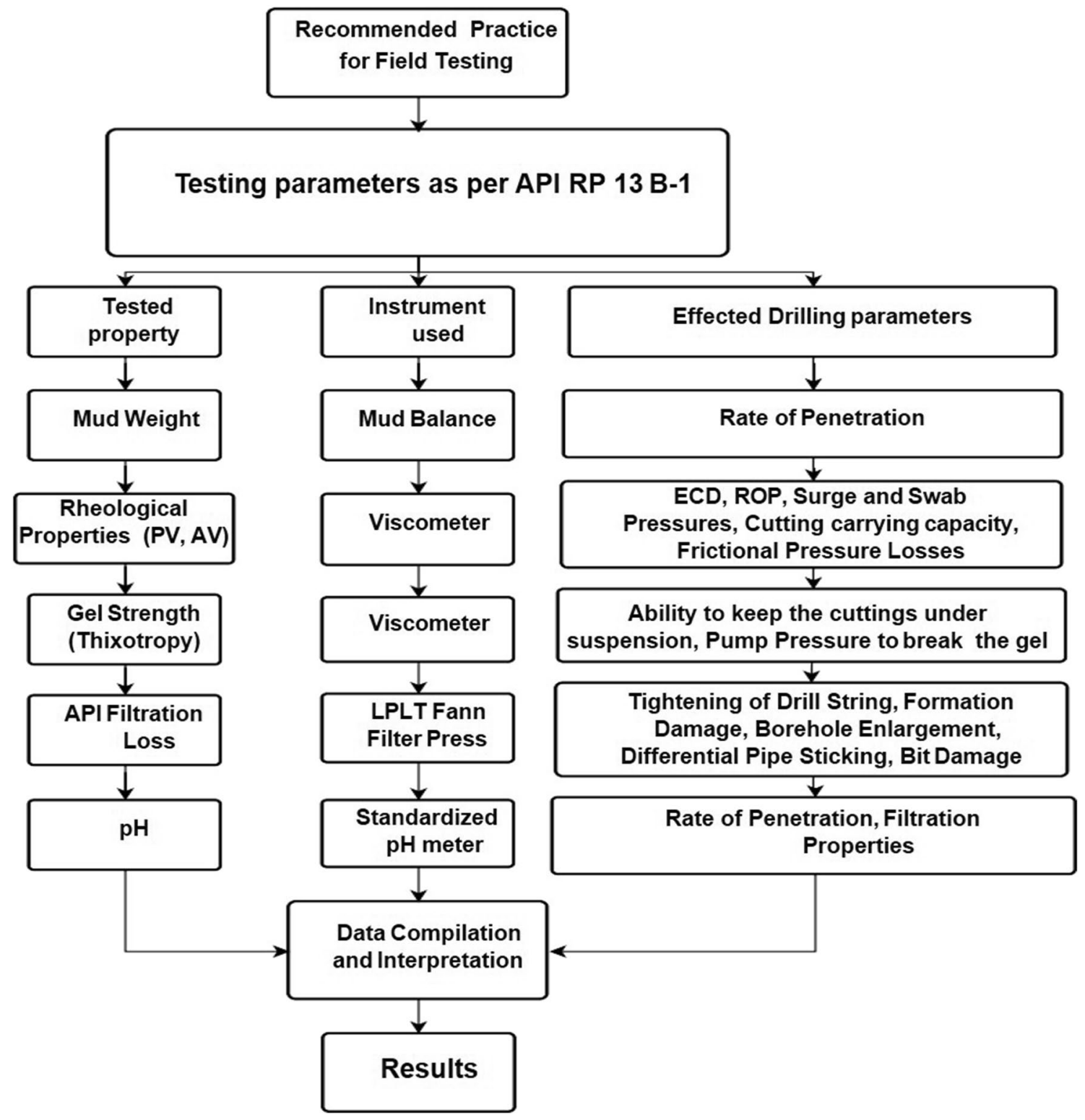

Fig. 1 Flowchart showing progressive methodology adopted and instruments used during current research work

sieve were all less than $74 \mu \mathrm{m}$ and were again filtered through a sieve of mesh size 230 , which retained particles larger than $63 \mu \mathrm{m}$. Hence, the desired particle size of 63-74 $\mu \mathrm{m}$ was prepared by mesh analysis of $-200+230$ (Fig. 3). The interpretation of grain size distribution and the presentation of natural data on a logarithmic scale are done. Wentworth's scale is based on logarithms to the base 2 and is most widely used in sedimentological studies. The phi $(\varphi)$ scale, where $\varphi=\left(-\log _{2} d\right)$, allows convenient interpolation of graphic data. The reason for using negative logarithm is sediment grain diameters (d), which is normally less than $1 \mathrm{~mm}$. Hence, we will have positive phi values for plotting (Bjorlykke 2010). The frequency distribution curve analysis of husk fibers is shown in Fig. 4.
Stage 3: Drilling fluid preparation and composition: Since the use of groundnut husk as a fluid loss retarder additive in the formulation of drilling fluids is novel to the industry, the formulations were kept simple with water, barite, $\mathrm{XCP}$, and groundnut husk (in varying concentrations) tested at two different particle sizes to study the effect of groundnut husk in the drilling fluid against the same formulations but using PAC in place of the proposed additive. The base mud for the different samples was prepared by gradually adding the Xanthum gum polymer to water and then allowing it to swell (Hossain and Wajheeuddin 2016). This mixture was agitated for about $30 \mathrm{~min}$ before introducing barite to the formulation. This base mud was prepared freshly for testing the different properties before adding the samples at different 

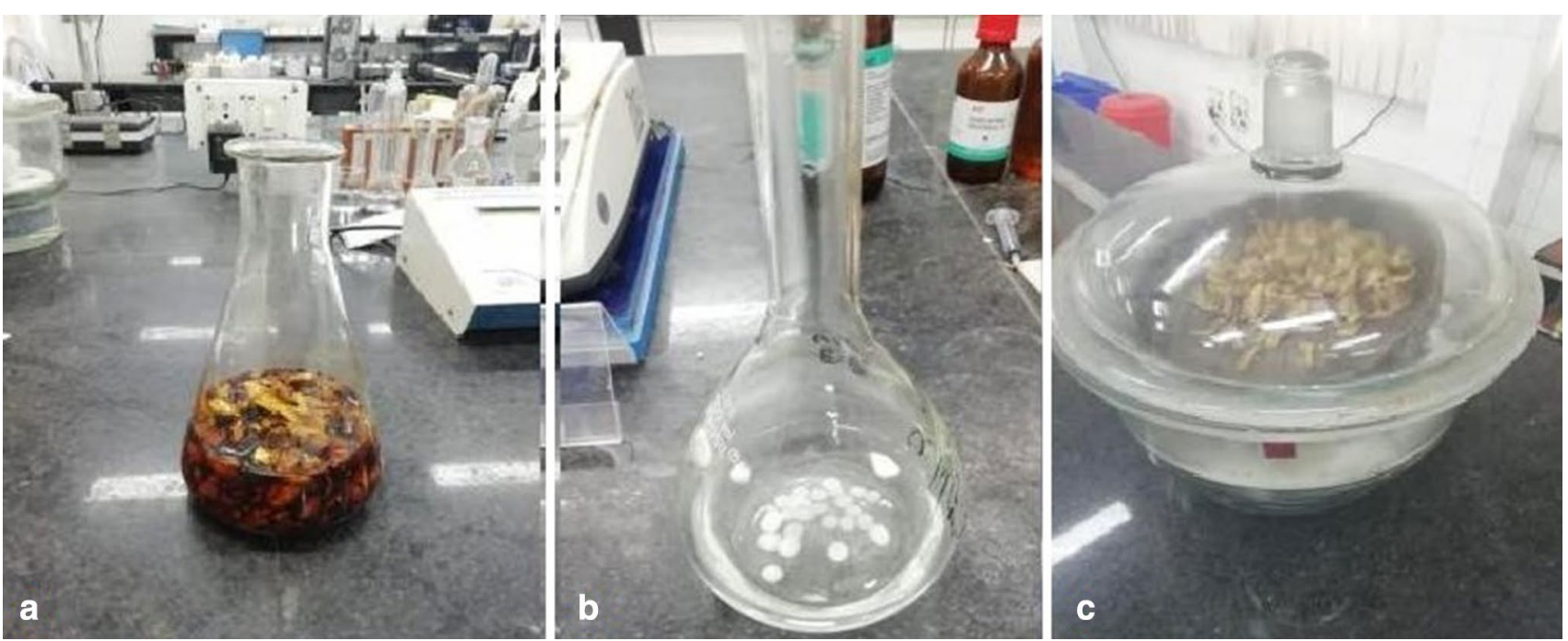

Fig. 2 Different steps involved in the preparation of fibers from groundnut husk in laboratory a raw sample soluble in alkali, $\mathbf{b}$ preparation of alkaline solution using $\mathrm{NaOH}$ tablets, $\mathbf{c}$ oven-dried sample in desiccator

Fig. 3 Instruments used while doing direct mesh analysis and their purpose, a sieve shaker instrument used for particle size analysis, b varying mesh sizes used for sample preparation
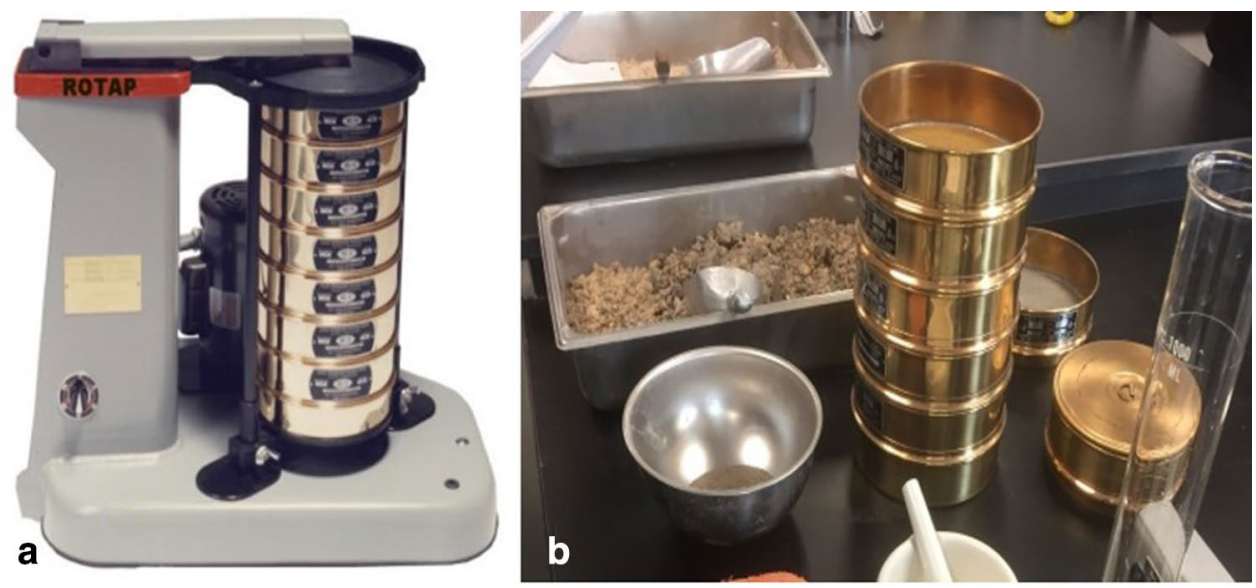

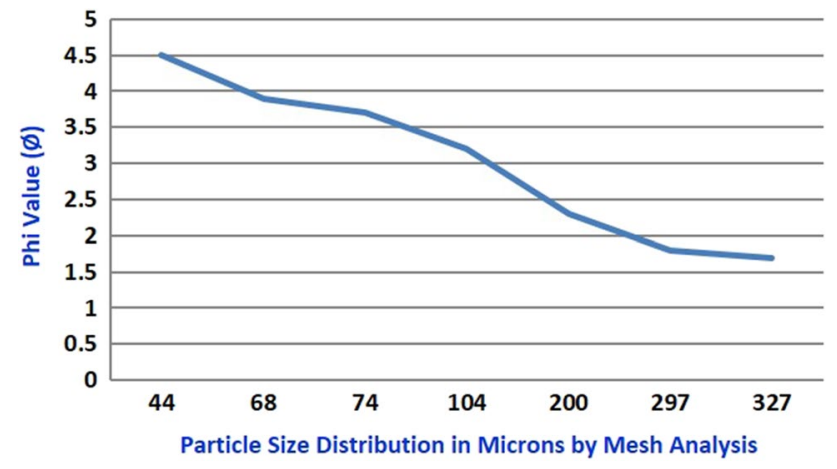

Fig. 4 Frequency distribution curve of husk fibers obtained by mesh analysis

concentrations and agitating it in a Hamilton Beach Mixer. The properties were tested before and after the hot roll. The drilling fluid preparation was made with the same procedure as was used for the base mud, but in this case, polyanionic cellulose was replaced with groundnut husk cellulose. Like the case above, the base mud was prepared freshly for testing the different properties before adding PAC at different concentrations and agitating it in a Hamilton Beach Mixer (Barry et al. 2015; Saboori et al. 2019). The properties were also tested before and after the hot roll to analyze the effects of temperature on the drilling fluid.

\section{Drilling fluid formulation}

The formulations were kept simple, and each of the properties was measured and compared for the best proposed size and concentration of the additive. The base mud formulation was as follows: water: $500 \mathrm{ml}$, barite: $22 \%$, i.e., equivalent to $110 \mathrm{~g}$, Xanthum gum polymer: $0.4 \%$, i.e., equivalent to $2 \mathrm{~g}$. Laboratory analysis of the development of three different types of drilling formulations is shown in Fig. 5. The 

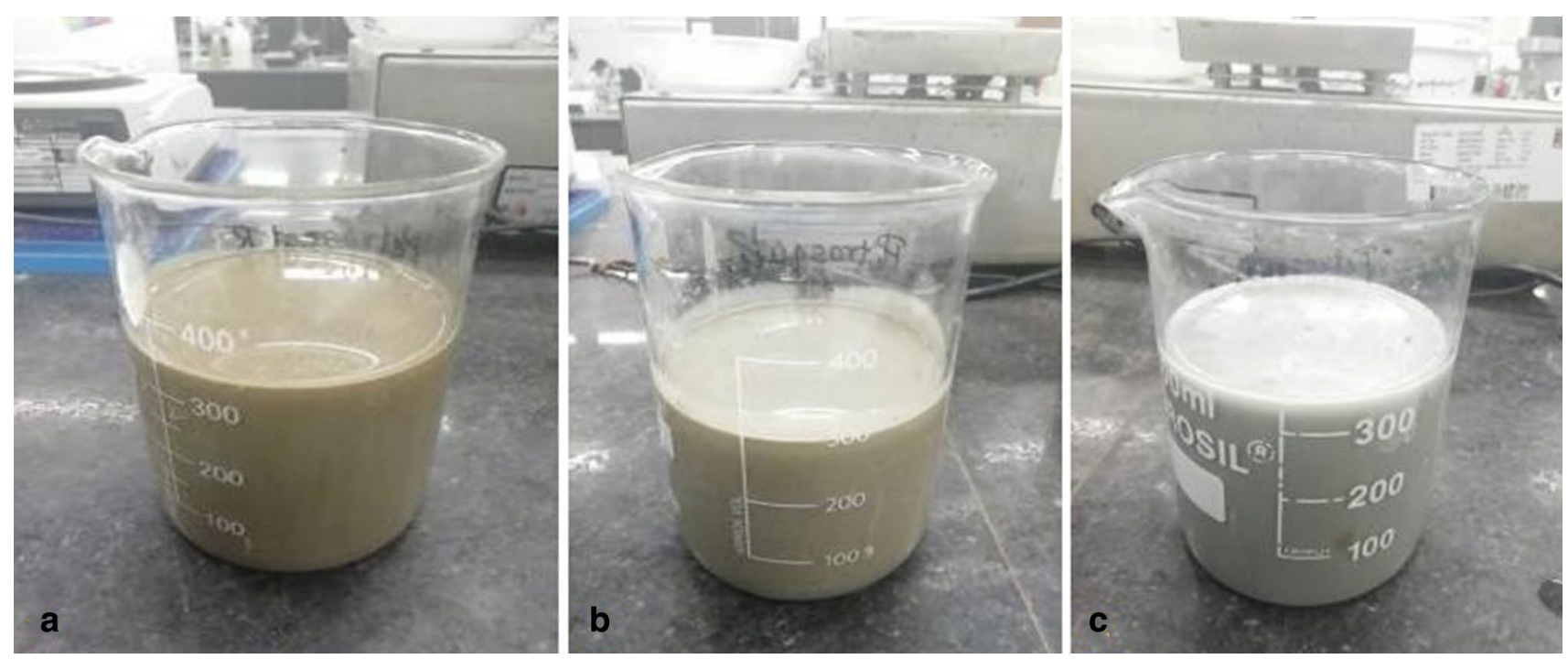

Fig. 5 Samples of the developed drilling formulations using different particle sizes of the proposed additive and PAC a $250-297 \mu$ m, b 63-74 $\mu \mathrm{m}, \mathbf{c}$ PAC

materials used in the formulation of drilling fluids are barite (BaSO4), polyanionic cellulose low viscosity grade (PACLVG), Xanthum gum polymer, distilled water, and finely ground husk. Table 1 shows laboratory data analysis for drilling fluid formulation and readings taken before \& after the hot roll. The apparatus used for testing out the properties of different formulations is low-pressure low-temperature (LPLT) Fann filter press, measuring cylinders, hot roller oven, stopwatch, filter paper, automatic viscometer, mud balance, Hamilton Beach Mud Mixer (Fig. 1). The major properties tested as per API recommendations are low-pressure low-temperature (LPLT) API filtration loss, apparent viscosity $(\mathrm{AV})$, plastic viscosity $(\mathrm{PV})$, yield strength (YP), gel strength (Gel0, Gel10), $\mathrm{pH}$, mud weight $(\rho)$. The details of drilling fluid formulations with proposed additives are listed in Table 1.

\section{Data interpretation}

The properties of mud are highly dependent on shear history and temperature; hence, it is of utmost significance to test the proposed mud cake composition in the laboratory prevailing the circumstances comparable to drilling a well. Many drilling mud additives degrade at high temperatures (Huang et al. 2016; Hamad et al. 2020). Consequently, the

Table 1 Drilling fluid formulation with proposed additive obtained from groundnut husk and PAC from $1 \%$ to $4 \%$ by weight

\begin{tabular}{|c|c|c|c|c|}
\hline Sample & $\begin{array}{l}\text { Size of particles } \\
(\mu \mathrm{m})\end{array}$ & Additives & $\begin{array}{l}\text { Concentration of addi- } \\
\text { tive }(\%)\end{array}$ & Formulation of drilling fluid \\
\hline Sample 1 & - & Barite $+\mathrm{XCP}$ & - & Water: $500 \mathrm{ml}$, barite: $110 \mathrm{~g}, \mathrm{XCP}: 2 \mathrm{~g}$ \\
\hline Sample 2 & 68 & Barite $+\mathrm{XCP}+\mathrm{PAC}$ & 1 & Water: $500 \mathrm{ml}$, barite: $110 \mathrm{~g}, \mathrm{XCP}: 2 \mathrm{~g}, \mathrm{PAC}: 1 \mathrm{~g}$ \\
\hline Sample 3 & $63-74$ & Barite $+\mathrm{XCP}+$ husk & 1 & Water: $500 \mathrm{ml}$, barite: $110 \mathrm{~g}, \mathrm{XCP}: 2 \mathrm{~g}$, Husk: $1 \mathrm{~g}$ \\
\hline Sample 4 & $250-297$ & Barite $+\mathrm{XCP}+$ husk & 1 & Water: $500 \mathrm{ml}$, barite: $110 \mathrm{~g}, \mathrm{XCP}: 2 \mathrm{~g}$, Husk: $1 \mathrm{~g}$ \\
\hline Sample 5 & 68 & Barite $+\mathrm{XCP}+\mathrm{PAC}$ & 2 & Water: $500 \mathrm{ml}$, barite: $110 \mathrm{~g}, \mathrm{XCP}: 2 \mathrm{~g}$, PAC: $2 \mathrm{~g}$ \\
\hline Sample 6 & $63-74$ & Barite $+\mathrm{XCP}+$ husk & 2 & Water: $500 \mathrm{ml}$, barite: $110 \mathrm{~g}, \mathrm{XCP}: 2 \mathrm{~g}$, Husk: $2 \mathrm{~g}$ \\
\hline Sample 7 & $250-297$ & Barite $+\mathrm{XCP}+$ husk & 2 & Water: $500 \mathrm{ml}$, barite: $110 \mathrm{~g}, \mathrm{XCP}: 2 \mathrm{~g}$, Husk: $2 \mathrm{~g}$ \\
\hline Sample 8 & 68 & Barite $+\mathrm{XCP}+\mathrm{PAC}$ & 3 & Water: $500 \mathrm{ml}$, barite: $110 \mathrm{~g}, \mathrm{XCP}: 2 \mathrm{~g}$, PAC: $3 \mathrm{~g}$ \\
\hline Sample 9 & $63-74$ & Barite $+\mathrm{XCP}+$ husk & 3 & Water: $500 \mathrm{ml}$, barite: $110 \mathrm{~g}, \mathrm{XCP}: 2 \mathrm{~g}$, Husk: $3 \mathrm{~g}$ \\
\hline Sample 10 & $250-297$ & Barite $+\mathrm{XCP}+$ Husk & 3 & Water: $500 \mathrm{ml}$, barite: $110 \mathrm{~g}, \mathrm{XCP}: 2 \mathrm{~g}$, Husk: $3 \mathrm{~g}$ \\
\hline Sample 11 & 68 & Barite $+\mathrm{XCP}+\mathrm{PAC}$ & 4 & Water: $500 \mathrm{ml}$, barite: $110 \mathrm{~g}, \mathrm{XCP}: 2 \mathrm{~g}$, PAC: $4 \mathrm{~g}$ \\
\hline Sample 12 & $63-74$ & Barite $+\mathrm{XCP}+$ husk & 4 & Water: $500 \mathrm{ml}$, barite: $110 \mathrm{~g}, \mathrm{XCP}: 2 \mathrm{~g}$, Husk: $4 \mathrm{~g}$ \\
\hline Sample 13 & $250-297$ & Barite $+\mathrm{XCP}+$ husk & 4 & Water: $500 \mathrm{ml}$, barite: $110 \mathrm{~g}, \mathrm{XCP}: 2 \mathrm{~g}$, Husk: $4 \mathrm{~g}$ \\
\hline
\end{tabular}


effect of temperature should be observed in all drilling fluid components and additives to corroborate their efficiency. To simulate the subsurface well conditions, the drilling fluids are hot rolled in the rolling oven at the same pressure and temperature likely to be encountered while drilling a well. The cells are cooled to room temperature; the rheological and filtration properties are then measured and compared to the same properties before testing. That is why it is essential to test the properties of the drilling fluid after hot roll to validate its effectiveness after the aging of the additive. The data generated during the laboratory analysis of current research work are plotted in excel, and systematic interpretation was carried out by comparing properties of different concentrations of proposed groundnut husk and PAC additives. The laboratory analysis results of readings taken before and after the hot roll are shown in Tables 2 and 3.

To analyze the laboratory data, the empirical formulas used are given below.
Table 2 Readings of various rheological properties of the developed drilling fluid formulations taken before the hot roll
Table 3 Readings of various rheological properties of the developed drilling fluid formulations taken after the hot roll

\begin{tabular}{|c|c|c|c|c|c|c|c|c|c|c|c|c|c|}
\hline & \multirow[t]{2}{*}{ Base Mud } & \multicolumn{4}{|c|}{$\begin{array}{l}\text { Groundnut husk } \\
(250-297) \mu \mathrm{m}\end{array}$} & \multicolumn{4}{|c|}{$\begin{array}{l}\text { Groundnut husk (63-74) } \\
\mu \mathrm{m}\end{array}$} & \multicolumn{4}{|l|}{ PAC } \\
\hline & & $1 \%$ & $2 \%$ & $3 \%$ & $4 \%$ & $1 \%$ & $2 \%$ & $3 \%$ & $4 \%$ & $1 \%$ & $2 \%$ & $3 \%$ & $4 \%$ \\
\hline$\theta 600$ & 43 & 37 & 49 & 47 & 56 & 40 & 41 & 47 & 53 & 80 & 90 & 165 & 360 \\
\hline$\theta 300$ & 35 & 29 & 34 & 33 & 39 & 29 & 31 & 32 & 36 & 60 & 63 & 103 & 280 \\
\hline$\theta 200$ & 32 & 27 & 32 & 29 & 35 & 26 & 28 & 29 & 32 & 51 & 52 & 87 & 161 \\
\hline$\theta 100$ & 26 & 23 & 27 & 26 & 28 & 22 & 26 & 27 & 26 & 38 & 39 & 71 & 101 \\
\hline$\theta 6$ & 16 & 13 & 17 & 16 & 17 & 13 & 17 & 17 & 16 & 16 & 16 & 16 & 13 \\
\hline$\theta 3$ & 15 & 11 & 15 & 15 & 15 & 11 & 15 & 15 & 13 & 14 & 13 & 15 & 15 \\
\hline PV & 8 & 8 & 15 & 14 & 17 & 11 & 10 & 15 & 17 & 20 & 27 & 62 & 80 \\
\hline YP & 27 & 21 & 19 & 19 & 22 & 18 & 21 & 17 & 19 & 40 & 36 & 41 & 200 \\
\hline AV & 21.5 & 18.5 & 24.5 & 23.5 & 28 & 20 & 20.5 & 23.5 & 26.5 & 40 & 45 & 82.5 & 180 \\
\hline Gel0 & 15 & 11 & 15 & 15 & 15 & 11 & 15 & 15 & 13 & 14 & 13 & 15 & 15 \\
\hline Gel10 & 21 & 15 & 21 & 21 & 23 & 16 & 21 & 23 & 27 & 16 & 16 & 21 & 23 \\
\hline Density & 1.13 & 1.13 & 1.13 & 1.13 & 1.13 & 1.13 & 1.13 & 1.13 & 1.13 & 1.13 & 1.13 & 1.13 & 1.13 \\
\hline Fluid loss (10) & 4.9 & 4.6 & 4.4 & 4.1 & 3.7 & 4.7 & 4.5 & 4 & 3.6 & 2.6 & 1.6 & 0.5 & 0 \\
\hline Fluid loss (20) & 8.6 & 5.7 & 5.3 & 4.9 & 5.6 & 5.6 & 5.3 & 4.91 & 4.7 & 2.9 & 2.2 & 1.4 & 0.4 \\
\hline Fluid loss (30) & 11.3 & 8.8 & 8.1 & 7.4 & 7.3 & 8.3 & 7.9 & 7.9 & 4.9 & 3.1 & 2.6 & 1.9 & 0.6 \\
\hline $\mathrm{pH}$ & 6.93 & 7.92 & 8.01 & 8.31 & 7.9 & 7.86 & 7.91 & 7.67 & 8.13 & 6.01 & 6.01 & 5.9 & 5.4 \\
\hline
\end{tabular}

\begin{tabular}{|c|c|c|c|c|c|c|c|c|c|c|c|c|c|}
\hline & \multirow[t]{2}{*}{ Base Mud } & \multicolumn{4}{|c|}{$\begin{array}{l}\text { Groundnut husk } \\
(250-297) \mu \mathrm{m}\end{array}$} & \multicolumn{4}{|c|}{$\begin{array}{l}\text { Groundnut husk (63-74) } \\
\mu \mathrm{m}\end{array}$} & \multicolumn{4}{|l|}{ PAC } \\
\hline & & $1 \%$ & $2 \%$ & $3 \%$ & $4 \%$ & $1 \%$ & $2 \%$ & $3 \%$ & $4 \%$ & $1 \%$ & $2 \%$ & $3 \%$ & $4 \%$ \\
\hline$\theta 600$ & 23 & 33 & 34 & 36 & 49 & 31 & 42 & 47 & 53 & 50 & 56 & 62 & 183 \\
\hline$\theta 300$ & 18 & 28 & 28 & 29 & 35 & 26 & 33 & 38 & 38 & 35 & 39 & 43 & 103 \\
\hline$\theta 200$ & 16 & 24 & 24 & 25 & 31 & 24 & 29 & 32 & 25 & 32 & 32 & 35 & 77 \\
\hline$\theta 100$ & 15 & 21 & 20 & 20 & 23 & 20 & 25 & 25 & 24 & 24 & 26 & 25 & 49 \\
\hline$\theta 6$ & 9 & 10 & 10 & 9 & 8 & 11 & 10 & 10 & 8 & 10 & 9 & 9 & 11 \\
\hline$\theta 3$ & 8 & 8 & 7 & 6 & 6 & 9 & 7 & 7 & 5 & 8 & 6 & 5 & 7 \\
\hline PV & 5 & 5 & 6 & 7 & 14 & 5 & 9 & 9 & 15 & 15 & 17 & 19 & 80 \\
\hline YP & 13 & 23 & 22 & 22 & 21 & 21 & 24 & 29 & 23 & 20 & 22 & 24 & 23 \\
\hline AV & 11.5 & 16.5 & 17 & 18 & 24.5 & 15.5 & 21 & 23.5 & 26.5 & 25 & 28 & 31 & 91.5 \\
\hline Gel0 & 8 & 8 & 7 & 6 & 6 & 9 & 7 & 7 & 5 & 8 & 6 & 5 & 7 \\
\hline Gel10 & 11 & 13 & 11 & 11 & 11 & 11 & 13 & 11 & 13 & 13 & 15 & 29 & 79 \\
\hline Density & 1.13 & 1.13 & 1.13 & 1.13 & 1.13 & 1.13 & 1.13 & 1.13 & 1.13 & 1.13 & 1.13 & 1.13 & 1.13 \\
\hline Fluid loss (10) & 20 & 19.6 & 11.6 & 6.3 & 5.8 & 23 & 14 & 9.5 & 3.6 & 9.8 & 5.9 & 0.9 & 0.3 \\
\hline Fluid loss (20) & 48 & 42 & 23.4 & 12.9 & 6.2 & 33 & 23.3 & 14.3 & 4.7 & 7.6 & 4.3 & 1.1 & 0.7 \\
\hline Fluid loss (30) & 61.6 & 83.1 & 33.8 & 16.3 & 10.9 & 35.8 & 34.8 & 16.5 & 5 & 4.5 & 3.9 & 1.3 & 1.1 \\
\hline pH & 6.01 & 7.31 & 7.91 & 7.63 & 7.92 & 7.01 & 7.57 & 7.67 & 7.15 & 5.79 & 5.71 & 5.65 & 5.70 \\
\hline
\end{tabular}


- Plastic viscosity: $P V=\theta 600-\theta 300$

- Yield point: $\mathrm{YP}=\theta 300-\mathrm{PV}$

- Apparent viscosity: AV= $=600 / 2$

\section{Rheological properties of resulting formulations with increasing concentrations of (250-297) $\mu \mathrm{m}$ husk, (63-74) $\mu \mathrm{m}$ husk, and PAC as proposed additives}

The rheological property is primarily concerned with the shear stress and shear rate relationship of drilling fluids, and it indicates the behavior of mud (Khamehchi et al. 2016; Vryzas and Kelessidis 2017). It is observed that the curves for dial reading increased with the corresponding dial speed and are in good agreement with the Bingham plastic model. Figure 6 shows that the shear stress increased with the concentration of the proposed additives at a given shear rate.

\section{Rheological properties (PV, AV) comparison}

Viscosity represents a measure of matter's resistance to a deforming force (Balhoff et al. 2011). This phenomenon is attributable to the attraction between molecules of a liquid and is the measure of the combined effects of adhesion and cohesion, to the effects of suspended particles and the liquid environment. For all drilling fluids, as temperature increases, the viscosity of base mud decreases (Sarah and Isehunwa 2015; Akinade et al. 2018). Viscosity can be expressed as either relative or in terms of absolute measurement. The relative measurements are the funnel viscosity and apparent viscosity. The viscosity measured by the marsh funnel is measured at only one rate of shear, but the temperature varies at each time of measurement (Al-Khdheeawi and Mahdi 2019; Alsabaa et al. 2020) The apparent viscosity of a fluid is the viscosity that fluid appears to have on a given instrument at a stated rate of shear. The absolute measurements are the quantitative values of the non-Newtonian characteristics, i.e., plastic viscosity, yield point, and gel strength.

Plastic viscosity can be defined as the resistance of a fluid to flow. According to the Bingham plastic model, $\mathrm{PV}$ is the slope between shear stress and shear rate. Fluids that have shear thinning and elevated viscosities are efficient for wellbore cleaning (Nasiri and Ashrafizadeh 2010). A measure of the internal resistance to fluid flow, plastic viscosity is attributable to the amount, type as well as the size of solids present in a given fluid (Idress and Hasan 2020). It is observed that decreasing the size of solids at a constant volume increases the value of the plastic viscosity. A drilling fluid formulation with higher plastic viscosity increases the equivalent circulation density (ECD); surge and swab pressures reduce the ROP all the while increasing the chances of differential sticking. The PV, AV trends for the formulations are illustrated in Fig. 7. It is observed that the viscosity
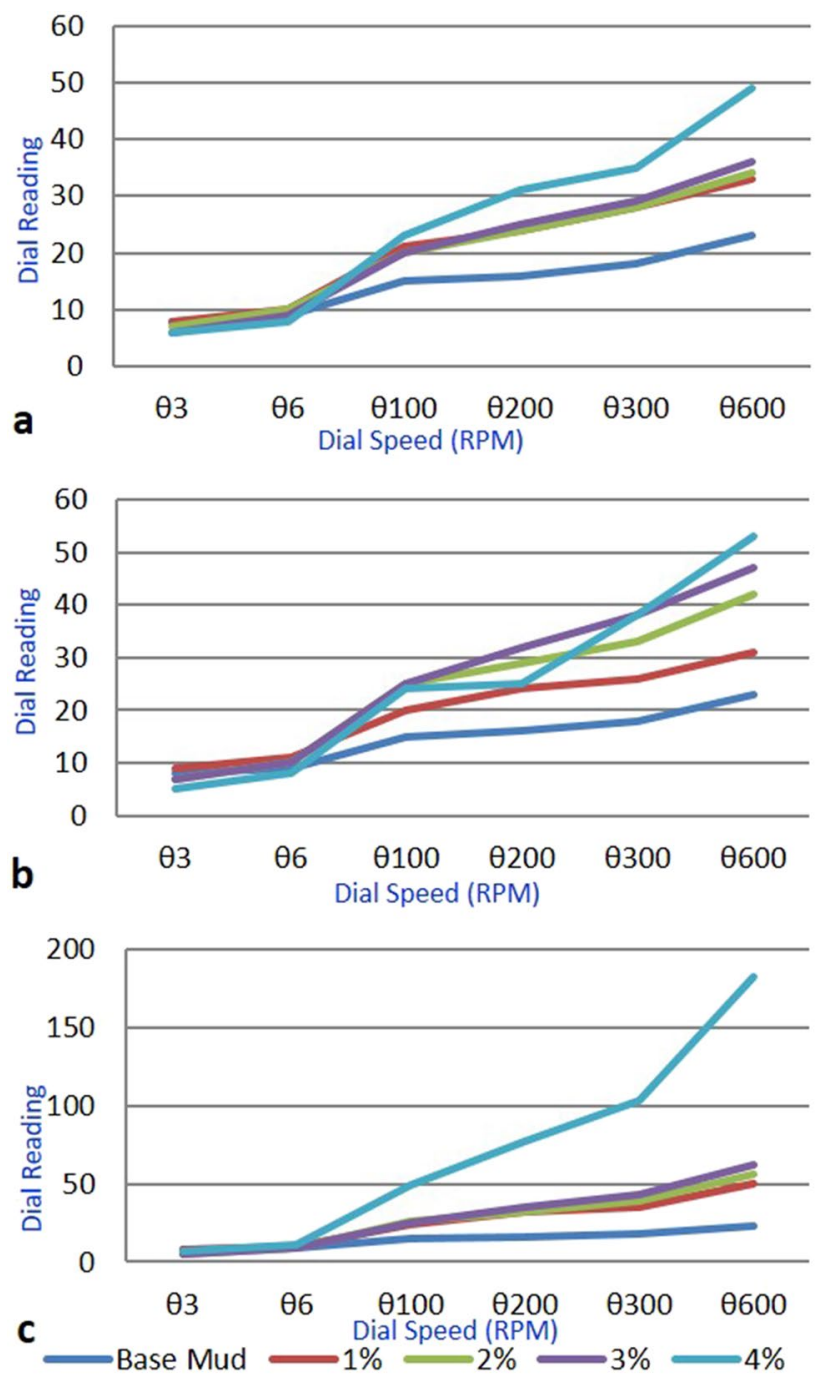

Fig. 6 Rheological comparison of developed drilling fluid formulations with base mud after hot roll a 250-297 $\mu \mathrm{m}, \mathbf{b} 63-74 \mu \mathrm{m}, \mathbf{c}$ PAC

values demonstrated by PAC were significantly larger than those shown by the husk formulated drilling fluids (Fig. 7).

\section{Yield point comparison}

A parameter of the Bingham plastic model, the yield point, is the yield stress extrapolated to a shear rate of zero. The yield point is the attractive force among the colloidal particles in the drilling fluid and represents the ability of the drilling fluid to lift the cuttings. The yield point is the resistance to initial flow and represents the stress required to start the fluid movement (Deng et al. 2020). This resistance is due to electrical charges located on or near the surface of the particles. Higher yield point leads to larger frictional pressure losses and an increase in the equivalent circulation density (ECD). The yield point trend illustrated by the (63-74) $\mu \mathrm{m}$ additive showed a peak value at $3 \%$ concentration and was

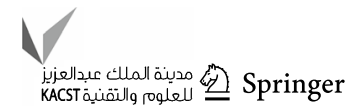



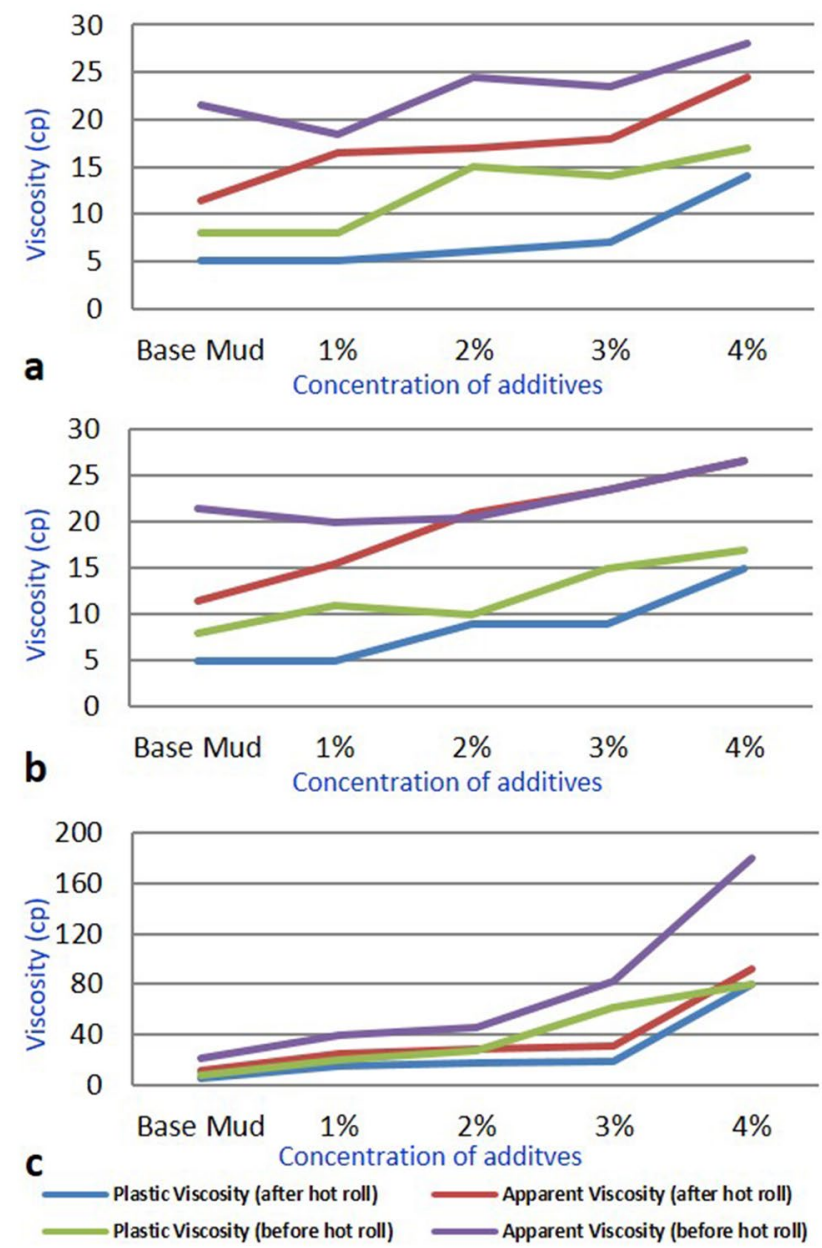

Fig. 7 PV, AV comparison of developed drilling fluid formulations with base mud before and after hot roll a 250-297 $\mu \mathrm{m}, \mathbf{b} 63-74 \mu \mathrm{m}$, c PAC

considerably higher than the peak demonstrated by PAC at the same concentration as shown in Fig. 8.

\section{Gel strength (thixotropic) comparison}

The gel strength of a drilling fluid is a measurement of the electrochemical forces under static conditions, which works to keep the cuttings in suspension (Ahmad and Federer 2018). These time-dependent forces cause gelling in the drilling fluid as it remains quiescent for a certain period when circulation stops. It is a measure of the same interparticle forces of a fluid as determined by the yield value, except that gel strength is measured under static conditions (Al-Hameedi et al. 2020b). The observations concluded the flat rheology profile of the fluid meaning minor changes of gel strength with time. The presence of a fragile gel is desirable as opposed to a progressive gel because it requires higher pump pressure to break the gel and begin continuous circulation (Jung et al. 2011). In the case of both the husk
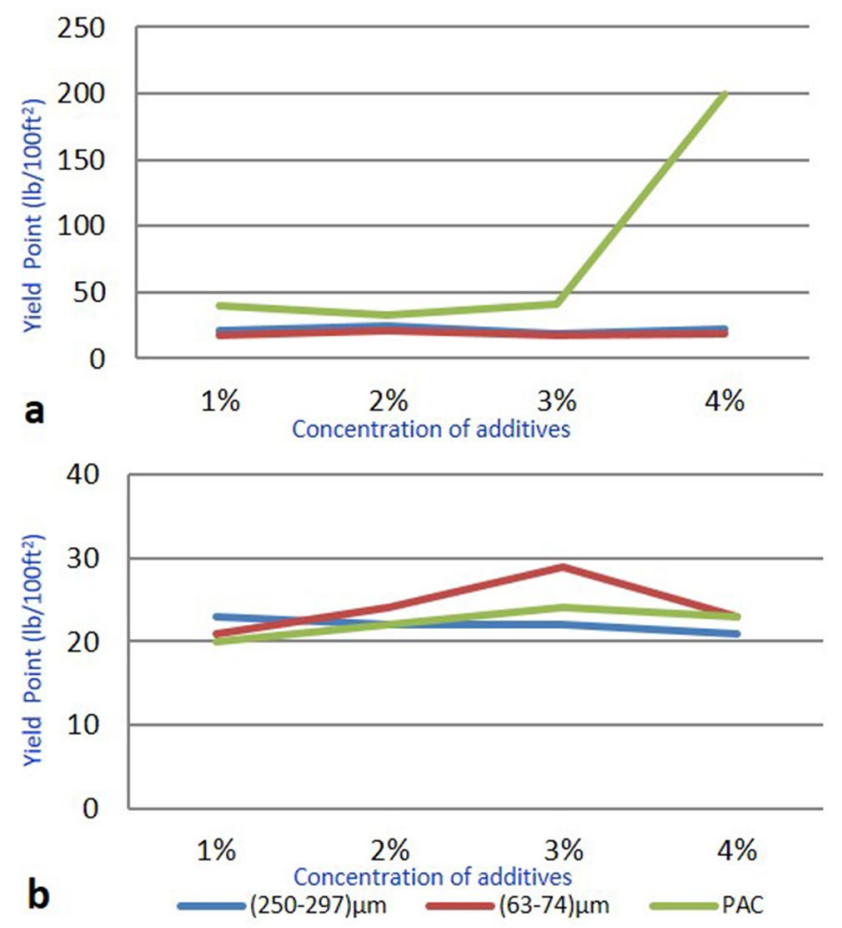

Fig. 8 Yield Strength comparison of developed drilling fluids formulations a before hot roll, $\mathbf{b}$ after hot roll

additives, the initial and final gel strengths are found to be increasing gradually, which indicates better suspension of cuttings and the gradual increase indicates the presence of a fragile gel (Fig. 9), whereas at $4 \%$ concentration, PAC formulated drilling fluid showed the presence of a progressive gel, which is undesirable as shown in Fig. 9.

\section{Filtration properties of resulting formulations}

For the formation of a filter cake, the drilling fluid must contain particles sizes slightly smaller than the pore openings of the formation (Alcheikh and Ghosh 2017; Saboori et al. 2018). Particles of a certain critical size stick at bottlenecks in the flow channels and form a bridge just inside the surface pores. Once a primary bridge is established, successively smaller particles are trapped, and thereafter, only filtrate invades the formation (Agwu et al. 2019). These are known as bridging particles that are trapped in the surface of the pores while the finer particles, at first, are carried deeper into the formation. The suspension of fine particles that enters into the formation, while the cake is established, is known as the mud spurt, and the liquid that enters subsequently is known as the filtrate (Yao et al. 2014). The rate of filtration and the increase in cake thickness depend upon whether or not the surface of the cake is subjected to fluid or mechanical erosion during the filtration process. When the mud is static as in this case, the filtrate volume and the cake 


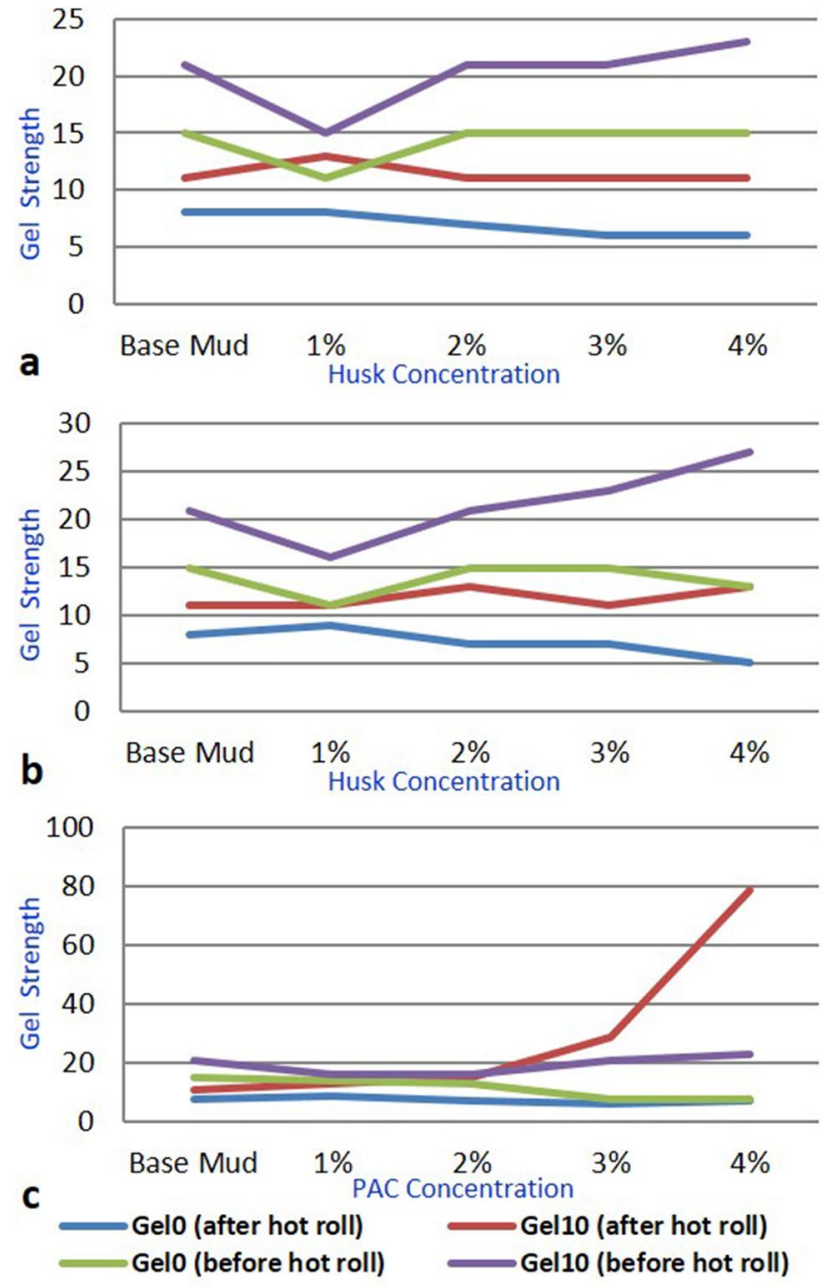

Fig. 9 Gel strength comparison of developed drilling fluid formulations before and after hot roll a 250-297 $\mu \mathrm{m}, \mathbf{b} 63-74 \mu \mathrm{m}, \mathbf{c}$ PAC

thickness increase in proportion to the square root of time, at a decreasing rate (Caenn et al. 2016).

As a result of the differential pressure exerted by the hydrostatic fluid column in the wellbore, a mud cake or filter cake having very low permeability that is formed against the walls of the borehole acts as a barrier between the fluid in the drilled borehole and the formation being drilled (Fattah and Lashin 2016). The loss of the filtrate of the drilling fluid into the formation is also an important parameter to consider, as a drilling formulation with higher filtration losses will soon start exhibiting increased values of density due to the loss of the fluid content from the mud into the formation. This can further lead to formation damage around the wellbore. Hence, a filter cake that is thin, impermeable, and dense ensures that a lesser amount of filtrate is lost to the formation, which helps prevent a change in the rheological properties of the drilling fluid by averting a change in the fluid density (Nasiri and Jafari 2016).
The trend of API filtration losses at $1 \%$ concentration of additives with the base mud

Figure 10a shows the trend of the filtrate losses of the formulated drilling fluids at $1 \%$ of the additive. The API filtration loss of the base mud after $30 \mathrm{~min}$ was $61.6 \mathrm{ml}$ and peaked at a filtrate loss of $48 \mathrm{ml}$ at $20 \mathrm{~min}$. The filtration properties exhibited by the 250-297 $\mu \mathrm{m}$ proposed additive showed a decrease in the API filtration loss of $12.5 \%$ at $20 \mathrm{~min}$ but then showed an increase in the losses of $25.8 \%$ at $30 \mathrm{~min}$. In contrast, the $63-74 \mu \mathrm{m}$ proposed additive showed a shallow descent trend with a decrease of $41.88 \%$ in the filtration loss. The fluid loss trend of PAC demonstrated a steep decline with a decrease of $92.69 \%$ in the filtration loss.

\section{The trend of API filtration losses at $2 \%$ concentration of additives with the base mud}

Figure $10 \mathrm{~b}$ shows the trend of the filtrate losses of the formulated drilling fluids at $2 \%$ of the additive. The API filtration loss of the base mud after $30 \mathrm{~min}$ was $61.6 \mathrm{ml}$ and peaked at a filtrate loss of $48 \mathrm{ml}$ at $20 \mathrm{~min}$. The filtration properties exhibited by the $250-297 \mu \mathrm{m}$ proposed additive showed a decrease in the API filtration loss of $45.13 \%$ at $30 \mathrm{~min}$. The 63-74 $\mu \mathrm{m}$ proposed additive showed a similar trend as its husk counterpart with a decrease of $43.51 \%$ overall. The fluid loss trend of PAC demonstrated a steep decline similar to its $1 \%$ equivalent with a decrease of $93.67 \%$ from the base mud.

\section{The trend of API filtration losses at 3\% concentration of additives with the base mud}

Figure 10c shows the trend of the filtrate losses of the formulated drilling fluids at $3 \%$ of the additive. The API filtration loss of the base mud after $30 \mathrm{~min}$ was $61.6 \mathrm{ml}$ and peaked at a filtrate loss of $48 \mathrm{ml}$ at $20 \mathrm{~min}$. The filtration properties exhibited by the 250-297 $\mu \mathrm{m}$ proposed additive showed a decrease in the API filtration loss of $73.54 \%$ at $30 \mathrm{~min}$. The trend for the 63-74 $\mu \mathrm{m}$ proposed additive showed a similar trend with a decrease of $73.21 \%$ overall. The fluid loss trend demonstrated by PAC was a lesser steep decline which was a perpetual continuation as its predecessors with a decrease in the filtration loss of $97.89 \%$ overall.

\section{The trend of API filtration losses at $4 \%$ concentration of additives with the base mud}

Figure 10d shows the trend of the filtrate losses of the formulated drilling fluids at $4 \%$ of the additive. The API filtration loss of the base mud after $30 \mathrm{~min}$ was $61.6 \mathrm{ml}$ and peaked at a filtrate loss of $48 \mathrm{ml}$ at $20 \mathrm{~min}$. The filtration properties exhibited by the $250-297 \mu \mathrm{m}$ proposed additive showed

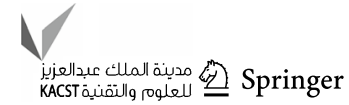



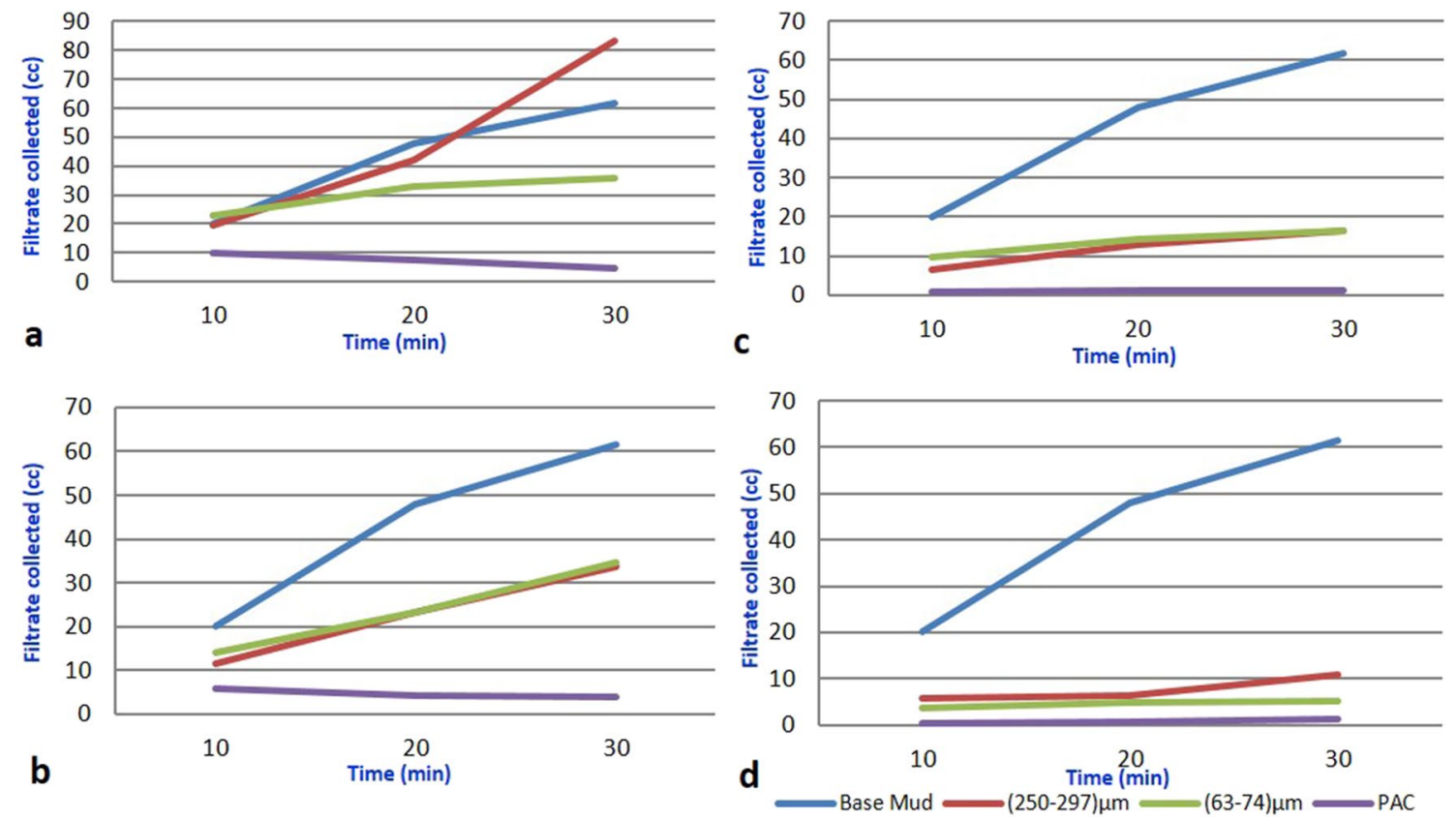

Fig. 10 API filtration losses of developed drilling fluid formulations after hot roll a at $1 \%$ sample concentration, b at $2 \%$ sample concentration, c At $3 \%$ sample concentration, $\mathbf{d}$ at $4 \%$ sample concentration

an overall decrease in the API filtration loss of $82.31 \%$ at $30 \mathrm{~min}$. The filtrate loss trend demonstrated by the $63-74 \mu \mathrm{m}$ proposed additive and PAC was observed to be strikingly similar. The 63-74 $\mu \mathrm{m}$ proposed additive showed a stable decline trend with a decrease of $91.88 \%$ in the filtration loss. The fluid loss trend of PAC illustrated a similar decline with a decrease of $98.21 \%$ in the filtration loss.

\section{The $\mathrm{pH}$ of resulting formulations}

A desirable drilling fluid is alkaline in nature and has a $\mathrm{pH}$ range of 9-10 as it ensures that the drilling fluid shows optimum rheological and filtration properties (Li et al. 2018; Gamal et al. 2019). This helps decrease the plastic viscosity which leads to an increase in the Rate of Penetration (ROP) thereby reducing the required pump pressure to circulate the mud to the surface, effectively reducing time, and helps in sustaining the drilling operations. Moreover, a lesser volume of filtrate ensures the formation of a thin, impermeable filter cake drastically reducing the chances of differential pipe sticking. A lesser $\mathrm{pH}$ means an increased amount of additives to achieve the right viscosity (Huang et al. 2016; Saboori et al. 2018). Hence, an optimum pH range ensures savings of the additives and operation costing. The $\mathrm{pH}$ comparison is carried out to have a comparative analysis of the proposed fluid. Figure 11 illustrates the $\mathrm{pH}$ trend of the developed formulations with increasing concentrations of additives. It is observed that the $\mathrm{pH}$ of the $250-297 \mu \mathrm{m}$ husk and $63-74 \mu \mathrm{m}$ husk as additives showed a slightly higher $\mathrm{pH}$

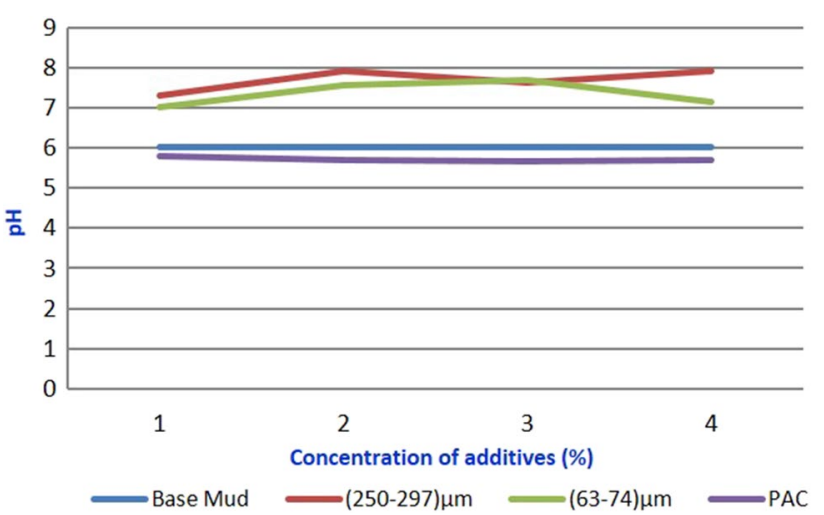

Fig. $11 \mathrm{pH}$ trend of the developed drilling fluid formulations with increasing concentration of the additives

compared to both the base mud and PAC at all concentrations. The $\mathrm{pH}$ of the base mud after the hot roll was 6.01. At $4 \%$ concentration, the $\mathrm{pH}$ of the $250-297 \mu \mathrm{m}$ husk was 7.92 while that of its 63-74 $\mu \mathrm{m}$ husk counterpart was 7.15, while at $4 \%$ concentration, PAC demonstrated a pH of 5.70 .

\section{Results and discussion}

The main objective of current research work is to develop an industrial-grade economically friendly, biodegradable drilling fluid additive that can perform its designated functions in a cost-effective manner. There has been a strong need for the 
development of clean drilling fluid additives that can replace hazardous chemical born traditional alternatives. We have given utmost consideration to various useful prerequisites of drilling fluid such as appropriate mud rheology, density, mud activity, fluid loss control. These were kept in consideration while preparing an eco-friendly substitute. The cellulose generated from groundnut husk was used to prepare a fluid loss retarder additive and rheological modifier as a prospective substitute of industrial PAC-LVG. The proposed drilling fluid is prepared and tested in accordance with API fluid testing procedure, and the results were systematically compared with the same formulation of PAC to validate the results in all aspects. The particle size and concentration were determined for the optimal results based on various observations. The determination of the optimum particle size for the proposed additive was based on two objectives. The first objective was based on the relationship of permeability of the filter cake with the mean diameter of the additive. The second objective was based on the uniform gradation of particle sizes or the width of the range of particle sizes for optimal results. Based on these observations, two different particle sizes (63-74 $\mu \mathrm{m}$ and 250-297 $\mu \mathrm{m})$ were tested and outcomes of comparative analysis are shown in this paper. The determination of ideal particle concentration is based on the observation of increasing concentrations of the husk additive as opposed to its PAC counterpart.

Since the properties of mud depend so much on shear history and temperature, the mud cake of the proposed additives was analyzed in the laboratory prevailing to analogous drilling conditions. The formulation of the base mud was kept simple, and the properties of the fluid were tested before as well as after hot roll, i.e., after the aging of the additive. The drilling fluid was tested for various mud properties such as mud rheology, density, Filtration Losses, pH, etc. These properties were measured according to the standard procedure, and the final observations were systematically compared and discussed in this segment of the paper. The comparative analysis of laboratory experiments in terms of various parameters is shown in Figs. 12, 13, 14, 15, 16 and 17. Various conclusions can be drawn from the comparative laboratory analysis between the groundnut husk based drilling fluid additive and PAC. The results of comparative analysis are shown in Figs. 12 and 13, where the bar charts are raveling the variation in shear stress in terms of the dial reading in a decreasing pattern from $\theta 600$ to $\theta 3$, before and after hot roll examination. In terms of dial readings of $\theta 600$, $\theta 300$, and $\theta 200$, it is observed that the proposed husk additive remained consistent throughout, while the PAC readings are showing variations at all the dial readings and increasing substantially as the concentration of the additive increased from 2 to $3 \%$ (Fig. 12). It is also noticed that the before hot roll readings of shear stresses remain in close range to each other for the proposed additive, but the PAC readings

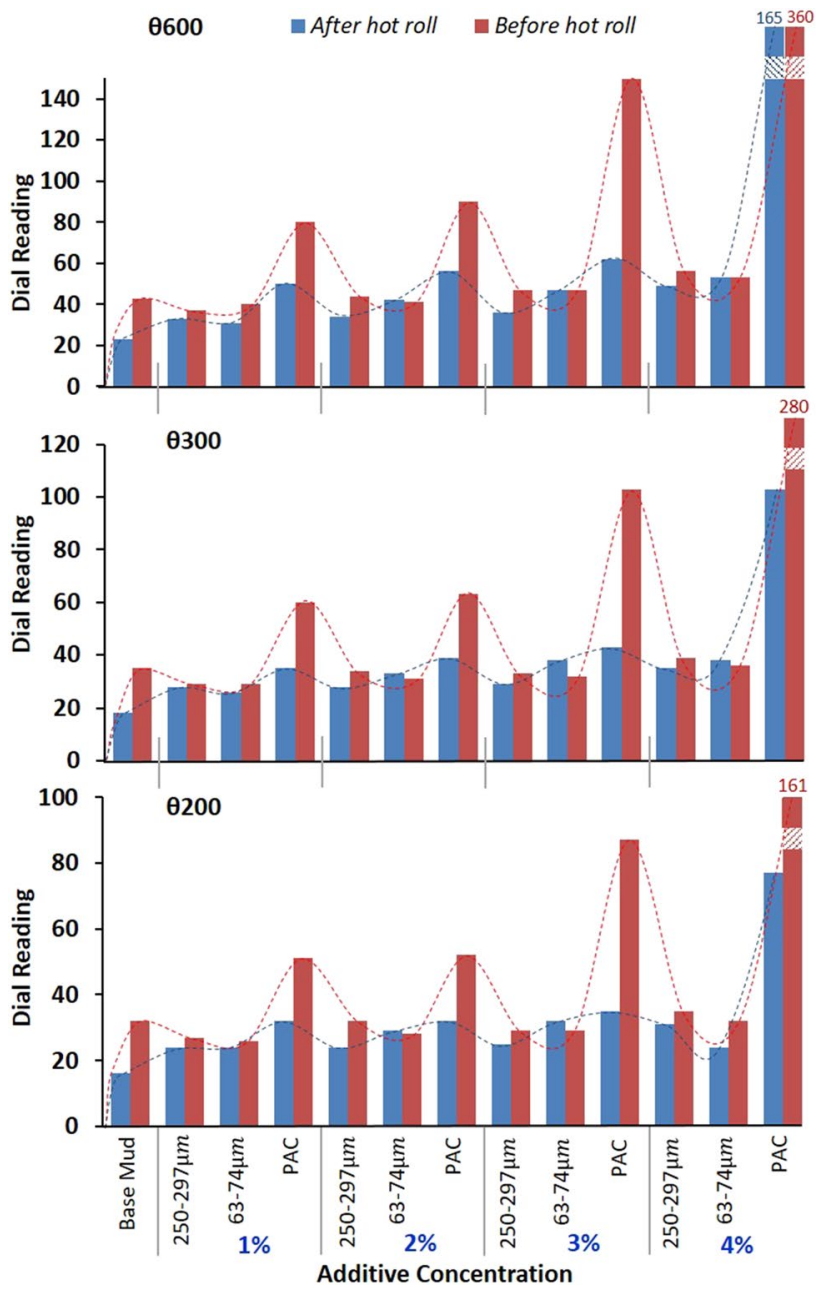

Fig. 12 A comparative analysis illustrating the variation in shear stress in terms of the dial reading in a decreasing pattern from $\theta 600$ to $\theta 200$ before and after hot roll. It is seen that the before hot roll readings of shear stresses remain in close range to each other for the proposed additive, but the PAC readings are showing increasing stresses after the hot roll at all concentrations

are showing increasing stresses after hot roll at all concentrations as shown in Fig. 12. Similar results are shown in Fig. 13 for dial readings of $\theta 100$, but the shear rate at dial readings of $\theta 6$ and $\theta 3$ is showing deviations between the before and after hot roll readings at $2-4 \%$ of concentrations. This is a significant finding of current research work that the proposed husk additives are showing similar patterns of stresses and essentially remain consistent as dial rates decrease as compared to PAC, which is clearly visible in the pattern of stresses plotted in Figs. 12 and 13. This deviation can easily be noticed by the variance between red and blue dashed lines shown in both the figures.

In terms of $\mathrm{PV}$ and $\mathrm{AV}$, it is observed that there is a gradual increase in both the values as the concentration of the additives increases from 1 to $4 \%$, but it remains in the close ranges to each other before and after hot roll

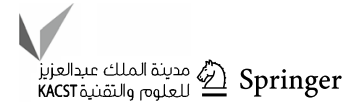




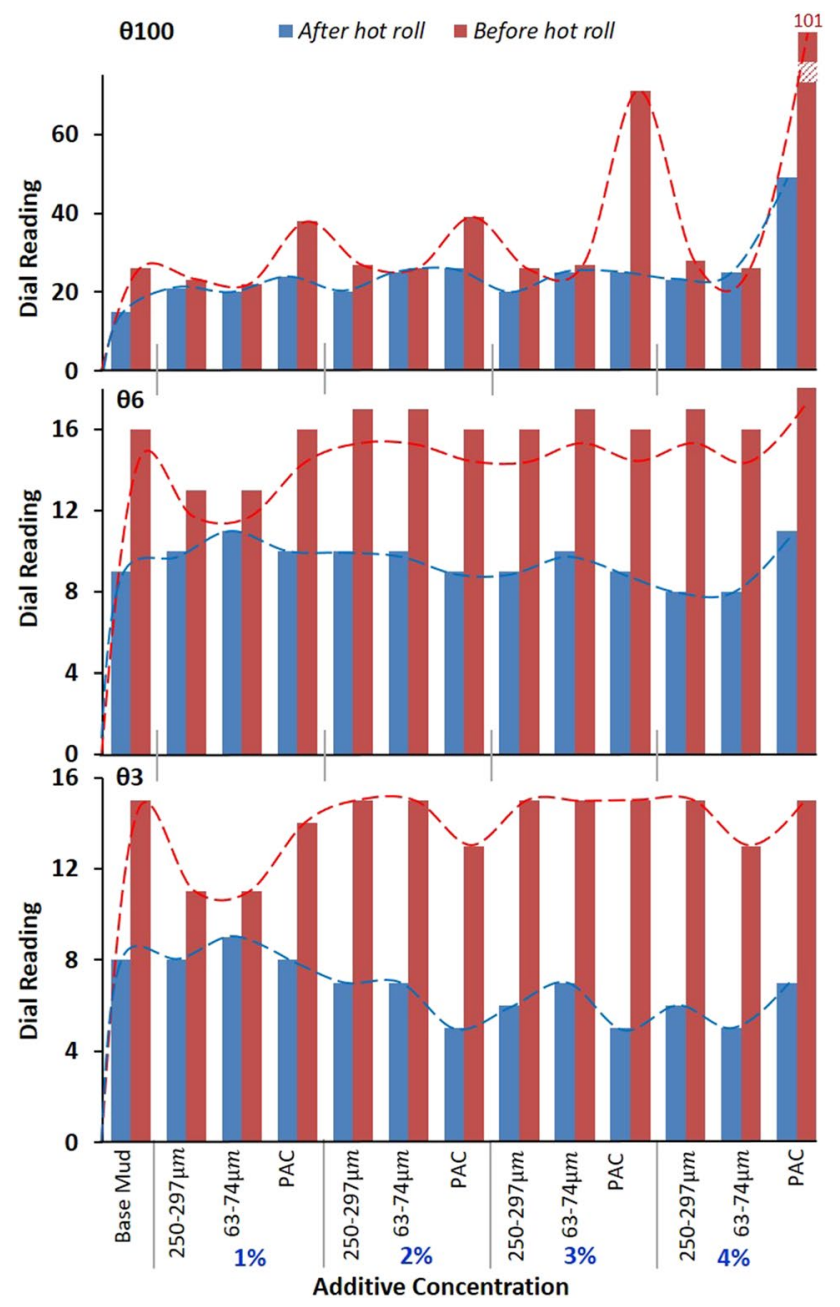

Fig. 13 A comparative analysis illustrating the variation in shear stress in terms of the dial reading in a decreasing pattern from $\theta 100$ to $\theta 3$ before and after hot roll. It is seen that the dial readings of $\theta 100$ are showing similar results shown in Fig. 12, but the shear rate at dial readings of $\theta 6$ and $\theta 3$ is showing deviations between the before and after hot roll readings at $2-4 \%$ concentrations

examinations (Fig. 14). However, in the case of PAC, it is observed that both the PV and AV values increase appreciably with the concentration and show great variations in the readings taken before and after a hot roll (Fig. 14). When compared for the YP value, it is observed that the before hot roll values of PAC stand out at all concentrations and show incredibly large variations from the after hot roll values for the same concentration (Fig. 15). While it is certainly observed that unlike its PAC counterpart, the husk additives remain consistent at all concentrations. The Gel0 and Gel10 readings are also showing large variations between the before and after hot roll readings (Fig. 15). The Gel10 readings of the PAC additive increased gradually after the hot roll, but it remained consistent for proposed additives. This is significant as it is indicative of the
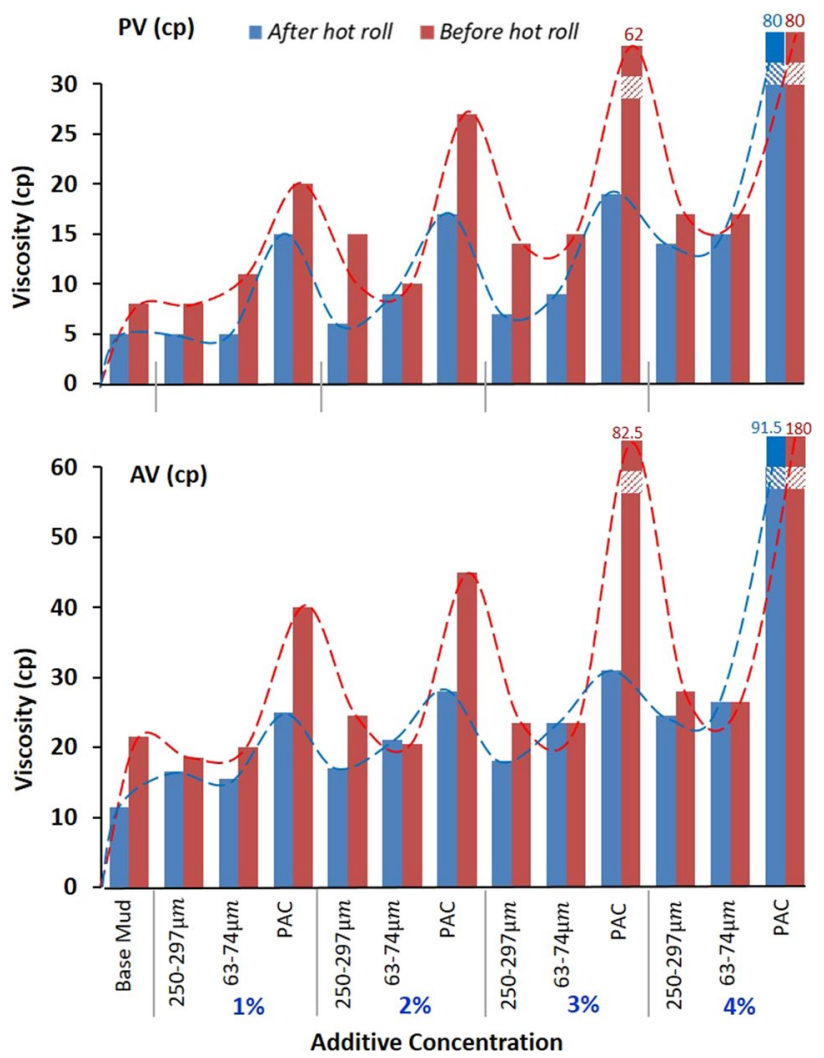

Fig. 14 A comparative analysis for PV, AV at varying concentrations before and after hot roll showing gradual increase in both the values as the concentration of the additives increased from 1 to $4 \%$

flat rheology profile of the husk additives. It also implies that the husk additives act as a fluid loss retarder without much deviation from its base rheology. This is of paramount importance as the proposed additive can be used to reduce the fluid loss in sensitive areas, where it needs to be done without much change to the rheology of the mud.

The trend of API filtration losses is shown in Fig. 16. The data plots are generated for fluid loss readings at 10, 20, and $30 \mathrm{~min}$, which indicate that the fluid Loss to be much higher after the hot roll as compared to before hot roll analysis. Based on fluid loss pattern at $30 \mathrm{~min}$, it is concluded that the fluid loss of husk additives of 63-74 $\mu \mathrm{m}$ particle size begins to resemble the pattern of PAC as concentration increases with a higher degree than the 250-297 $\mu \mathrm{m}$ particle size additive, although the PAC still shows the least amount of filtration losses (Fig. 16). The 63-74 $\mu \mathrm{m}$ particle size additive shows a similar fluid loss pattern at $4 \%$ concentration after hot roll like that of PAC with a very high rate of success, while remaining consistent and illustrating a flat rheology profile. It is observed that the $\mathrm{pH}$ value of the PAC after the hot roll is considerably less than the husk additives. The proposed husk additives steadily maintain a higher $\mathrm{pH}$ level 

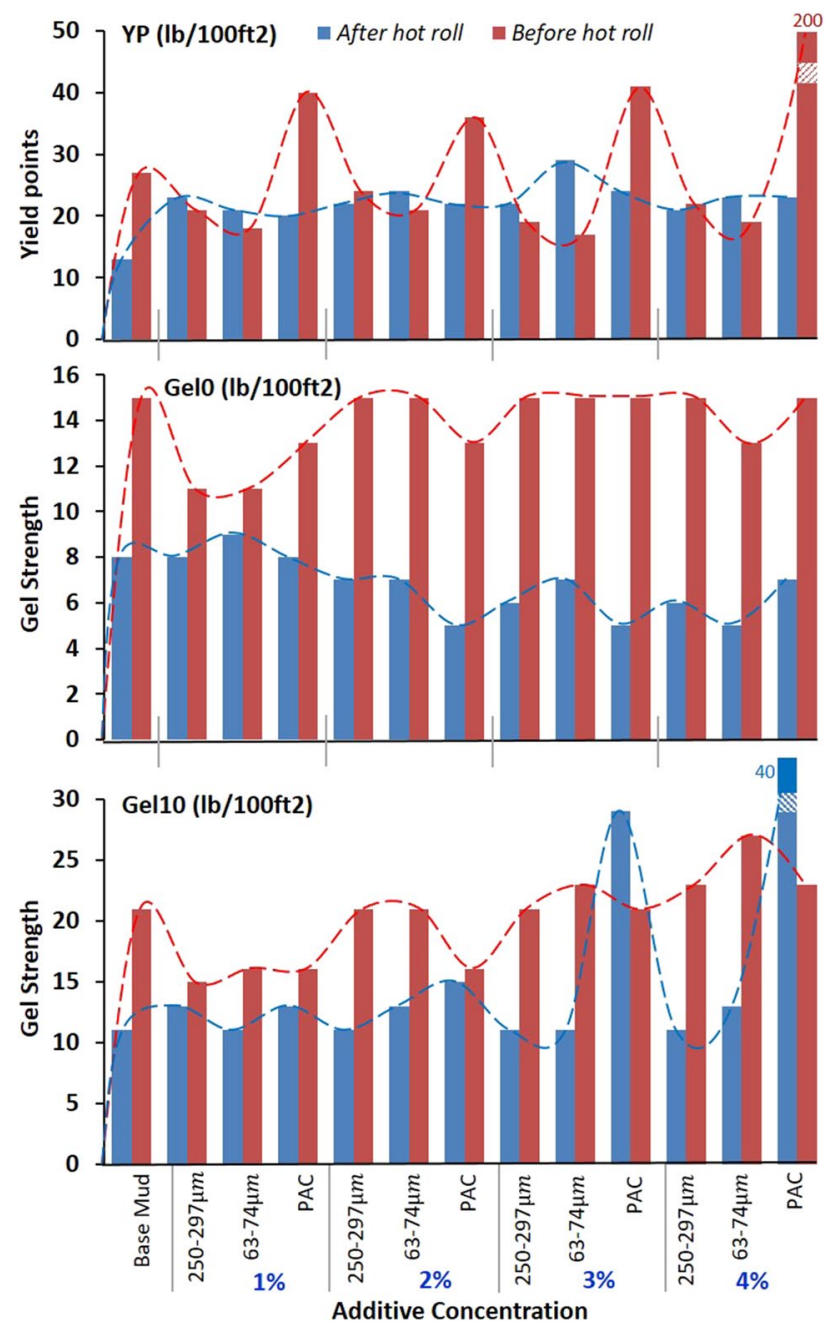

Fig. 15 Comparative analysis for YP, Gel0, Gel10 at varying concentrations before and after hot roll is shown. The YP values of PAC showing that the before hot roll values are incredibly high and showing variations from the after hot roll values for a similar concentration. Similarly, the Gel0 and Gel10 readings are also showing large variations between the before and after hot roll readings at all the concentrations. It is also noticed that the Gel10 readings of PAC at $3-4 \%$ concentration are showing abnormal behavior

at all concentrations before and after the hot roll analysis (Fig. 17).

The 63-74 $\mu \mathrm{m}$ additive remained more consistent in rheological aspects as compared to 250-297 $\mu$ m husk, while both were largely consistent as compared to PAC. Thus, it can be validated from above-discussed observations that the groundnut husk additives developed during current research work are an industrial-grade product based on systematic investigations and analysis/comparison. It can provide an extremely similar reduction in fluid losses as that of PACLVG, while simultaneously being more consistent, illustrating a flat rheology profile and being $50.79 \%$ more costeffective than PAC-LVG.
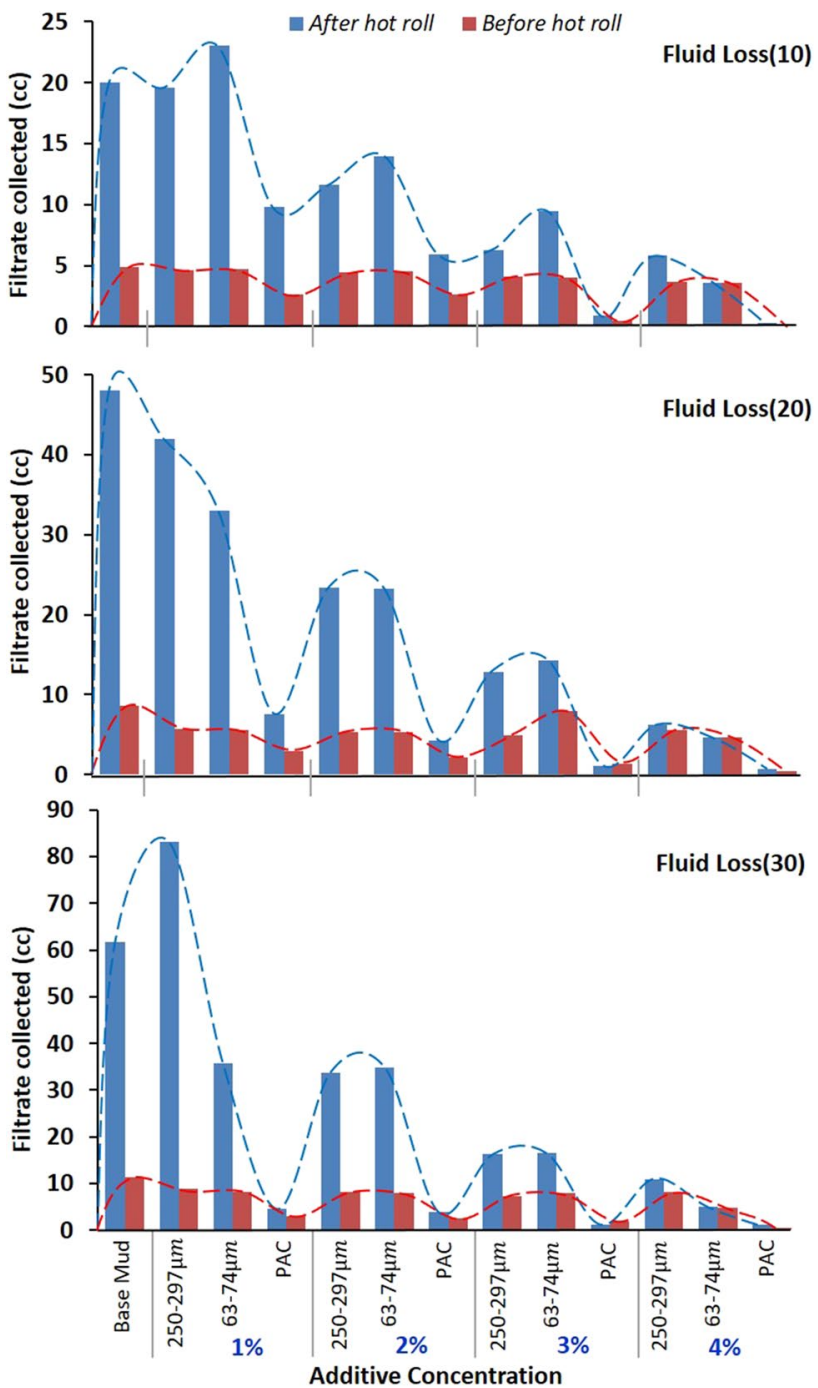

Fig. 16 A graphical interpretation illustrating the API filtration losses as a function of time at 10,20 , and $30 \mathrm{~min}$ before and after hot roll. Incredibly large variations can be seen between before and after hot roll readings, particularly at $1-2 \%$ concentrations

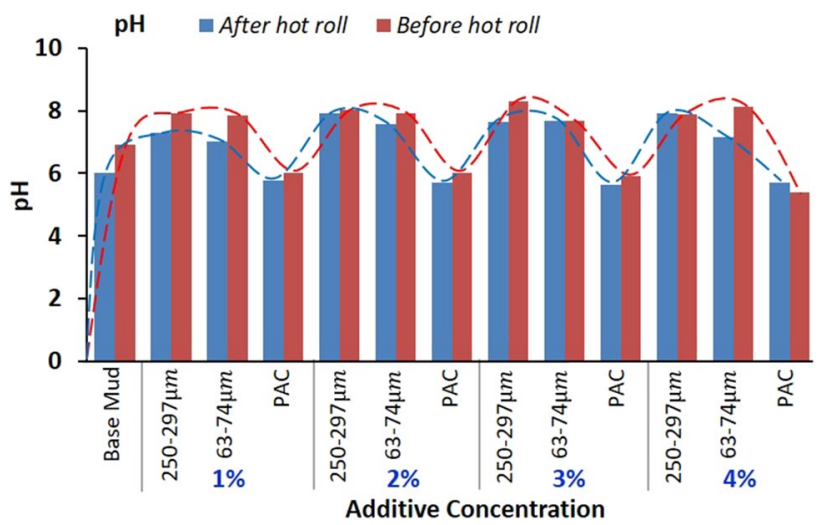

Fig. 17 A comparative analysis of $\mathrm{pH}$ at varying concentrations before and after hot roll

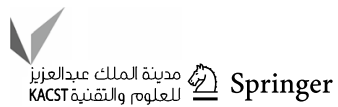


The cost-effectiveness of any product is a prime concern for any drilling operation. Nowadays, the adverse effect of drilling operation on the environment is considered as one of the major worries for petroleum industries, which should be taken into consideration to virtually eliminate the unnecessary expenses of improving the wasting quality before disposing it into the environment (Davarpanah 2018). The cost of drilling fluid additives varies geographically in a very wide range (Liu et al. 2016). The comparative cost analysis for industrial-grade conventional and proposed drilling fluid additives is carried out to understand the economic probabilities based on the published literature and our research work. To prepare a cost-effective drilling fluid, it is prerequisite that the base material should be easily available as per the industrial requirement at economic cost (Amanullah and Yu 2005; Haider et al. 2019). To validate this hypothesis, we have chosen the groundnut husk for the generation of cellulose as an eco-friendly additive, which is easily available in most parts of the world, inexpensive and the waste product of the food industries. The resulting formulations with 250-297 $\mu \mathrm{m}, 63-74 \mu \mathrm{m}$ particle size of husk and PAC as proposed additives, variable cost scenarios emerge. The average price of Xanthum gum polymer (XCP) ranges between Rs. 200 and 225 per $\mathrm{kg}$ with a median price of approx. Rs. 210 per kg. Similarly, the median price of Barite is approx. Rs. 14.5 per kg, and for the PAC-LVG it is approx. Rs. 184 per $\mathrm{kg}$. The median price of groundnut husk is approx. Rs. 3-3.5 per kg, and the median price of sodium hydroxide is approx. Rs. 33-34 per kg. So based on these mean values of base composition, the cost of preparation of $500 \mathrm{ml}$ of base fluid will be around Rs. 2 . The cost of preparing $500 \mathrm{ml}$ groundnut husk drilling fluid at $4 \%$ concentration will cost around Rs. 2.8 , and the cost of $500 \mathrm{ml}$ of drilling fluid with the same concentration of PAC-LVG will cost around Rs. 5.70. Thus, the groundnut husk additive is $50.79 \%$ more cost-efficient than the industrial PAC-LVG, and this becomes a hundredfold when used for oil and gas drilling operations.

Hence, based on the above observations of present investigation and comparative analysis, it is successfully demonstrated that the groundnut husk additive mainly of 63-74 $\mu \mathrm{m}$ particle size shows more consistency as compared to PAC on all parameters as discussed in this paper. It provides a reduction in fluid loss without deviation from base rheology, which is largely comparable with PAC and having less environmental impact due to its biodegradable nature. Lastly, we conclude that the groundnut husk additive can be used in place of PAC-LVG, such that it reduces the fluid loss while retaining its rheological behavior and hence is better suited for drilling hydrocarbon exploration wells in geologically complex scenarios.

\section{Conclusions}

The outcome of the current research work suggests that the groundnut husk can be successfully used as a cost-effective biodegradable alternative to industrial-grade PAC-LVG, which acts to reduce the API Filtration losses. The key outcomes of the laboratory analysis and data interpretation are summarized as follows,

1. Cellulose generated from groundnut husk is proposed as a fluid loss retarder additive. The $63-74 \mu \mathrm{m}$ proposed additive showed a stable decline trend with a decrease of $91.88 \%$ in the filtration loss at $5.0 \mathrm{ml}$ as opposed to a decrease of $98.21 \%$ in the filtration loss at $1.1 \mathrm{ml}$ for PAC.

2. The rheological properties illustrated by the proposed additives do not show much deviation from the base mud in terms of viscosity, yield strength, and gel strength. The mud weight at $1.13 \mathrm{~g} / \mathrm{cc}$ remained constant for all the formulations, while the higher $\mathrm{pH}$ values are observed for all the husk formulations as compared to PAC.

3. The mud cake permeability decreased with mean particle diameter as filtrate volume decreased from 250 to $297 \mu \mathrm{m}$ sample to $63-74 \mu \mathrm{m}$ sample. The least fluid loss is obtained at the finer end of the particle range, i.e., uniform gradation of particle size is of secondary importance as compared to the particle range as it will result in pore openings for the finer particles to pass through and result in fluid loss.

4. The groundnut husk additive was found to be $50.79 \%$ more cost-efficient than the industrial PAC-LVG, and this cost-effectiveness increases exponentially when used at an industrial level for actual drilling operations.

5. It is thus concluded that the proposed groundnut husk additive acts as a more cost-efficient filtrate retarder additive without much deviation from base rheology and is therefore recommended as a suitable alternative to PAC-LVG.

Acknowledgements We gratefully acknowledge the support received from the University of Petroleum and Energy Studies (UPES), Dehradun for conducting this research work. We would also like to thank Mr. Vishesh Nath, GM (Chem), R\&D at IDT, ONGC, Dehradun, for their valuable guidance and providing the opportunity to conduct laboratory experiments during this research project. Ms. Anjali Sharma leads to perform the laboratory experiments, and finally, all the authors synchronized the acquired data, made interpretations and modeling, defined outcomes, and wrote this paper.

\section{Compliance with ethical standards}

Conflict of interest All authors declare that there is no conflict of interest. 
Open Access This article is licensed under a Creative Commons Attribution 4.0 International License, which permits use, sharing, adaptation, distribution and reproduction in any medium or format, as long as you give appropriate credit to the original author(s) and the source, provide a link to the Creative Commons licence, and indicate if changes were made. The images or other third party material in this article are included in the article's Creative Commons licence, unless indicated otherwise in a credit line to the material. If material is not included in the article's Creative Commons licence and your intended use is not permitted by statutory regulation or exceeds the permitted use, you will need to obtain permission directly from the copyright holder. To view a copy of this licence, visit http://creativecommons.org/licenses/by/4.0/.

\section{References}

Agwu OE, Akpabio JU (2018) Using agro-waste materials as possible filter loss control agents in drilling muds: a review. J. Pet. Sci. Eng. 163:185-198

Agwu OE, Akpabio JU, Archibong GW (2019) Rice husk and saw dust as filter loss control agents for water-based muds. Heliyon. https://doi.org/10.1016/j.heliyon.2019.e02059

Ahmad KM, Federer G (2018) An experimental study to investigate the influence of temperature and pressure on the rheological characteristics of "Glydril" water-based muds. J Oil, Gas Petrochemical Sci 1:48-52. https://doi.org/10.30881/jogps.00010

Akinade AE, Wilfred OC, Akin-Taylor AM (2018) Improving the rheological properties of drilling mud using local based materials. Am J Eng Res AJER 7:58-63

Alcheikh IM, Ghosh B (2017) A comprehensive review on the advancement of non-damaging drilling fluids. Int J Petrochemistry Res 1:61-72. https://doi.org/10.18689/ijpr-1000111

Al-Hameedi ATT, Alkinani HH, Dunn-Norman S et al (2020a) Experimental investigation of bio-enhancer drilling fluid additive: can palm tree leaves be utilized as a supportive ecofriendly additive in water-based drilling fluid system? J Pet Explor Prod Technol 10:595-603. https://doi.org/10.1007/s1320 2-019-00766-7

Al-Hameedi ATT, Alkinani HH, Dunn-Norman S et al (2020b) Experimental investigation of environmentally friendly drilling fluid additives (mandarin peels powder) to substitute the conventional chemicals used in water-based drilling fluid. J Pet Explor Prod Technol 10:407-417. https://doi.org/10.1007/s13202-019-0725-7

Al-Khdheeawi EA, Mahdi DS (2019) Apparent viscosity prediction of water-based muds using empirical correlation and an artificial neural network. Energies 12:3067. https://doi.org/10.3390/ en 12163067

Alsabaa A, Gamal H, Elkatatny S, Abdulraheem A (2020) Realtime prediction of rheological properties of invert emulsion mud using adaptive neuro-fuzzy inference system. Sensors 20:1669. https://doi.org/10.3390/s20061669

Alsabagh AM, Abdou MI, Ahmed HES et al (2015) Evaluation of some natural water-insoluble cellulosic material as lost circulation control additives in water-based drilling fluid. Egypt J Pet 24:461-468. https://doi.org/10.1016/j.ejpe.2015.06.004

Amanullah M, Yu L (2005) Environment friendly fluid loss additives to protect the marine environment from the detrimental effect of mud additives. J Pet Sci Eng 48:199-208. https://doi. org/10.1016/j.petrol.2005.06.013

Amanullah M, Marsden JR, Shaw HF (1997) An experimental study of the swelling behaviour of mudrocks in the presence of waterbased mud systems. J Can Pet Technol 36:45-49. https://doi. org/10.2118/97-03-04

Amanullash M (2007) Screening and evaluation of some environment-friendly mud additives to use in water-based drilling muds. In: E\&P environmental and safety conference. Society of Petroleum Engineers

Balhoff MT, Lake LW, Bommer PM et al (2011) Rheological and yield stress measurements of non-Newtonian fluids using a Marsh Funnel. J Pet Sci Eng 77:393-402. https://doi. org/10.1016/j.petrol.2011.04.008

Barry MM, Jung Y, Lee JK et al (2015) Fluid filtration and rheological properties of nanoparticle additive and intercalated clay hybrid bentonite drilling fluids. J Pet Sci Eng 127:338-346. https://doi.org/10.1016/j.petrol.2015.01.012

Bjorlykke K (2010) Introduction to petroleum geology. Springer, Berlin

Caenn R, Darley HCH, Gray GR (2016) Composition and properties of drilling and completion fluids, 7th edn. Gulf Professional Publishing, Houston

Chilingarian GV, Alp E, Caenn R et al (2007) Drilling fluid evaluation using yield point-plastic viscosity correlation. Energy Sources 8:233-244. https://doi.org/10.1080/009083186089460 52

Cline JT, Teeters DC, Andersen MA (1989) Wettability preferences of minerals used in oil-based drilling fluids. In: SPE international symposium on oilfield chemistry. Society of Petroleum Engineers

Davarpanah A (2018) A visual investigation of different pollutants on the rheological properties of sodium/potassium formate fluids. Appl Water Sci 8:117. https://doi.org/10.1007/s13201-018-0762-2

Deng S, Kang C, Bayat A et al (2020) Rheological properties of claybased drilling fluids and evaluation of their hole-cleaning performances in horizontal directional drilling. J Pipeline Syst Eng Pract. https://doi.org/10.1061/(ASCE)PS.1949-1204.0000475

Elkatatny S (2019) Enhancing the rheological properties of water-based drilling fluid using micronized starch. Arab J Sci Eng 44:54335442. https://doi.org/10.1007/s13369-019-03720-1

Elochukwu H, Sia LKSL (2019) Improved filtration properties of polystyrene nanoparticle additives to water based drilling fluid. Conf Ser Mater Sci Eng 495:12072. https://doi.org/10.1088/1757899x/495/1/012072

Fatihah Majid NF, Katende A, Ismail I et al (2019) A comprehensive investigation on the performance of durian rind as a lost circulation material in water based drilling mud. Petroleum 5:285-294. https://doi.org/10.1016/j.petlm.2018.10.004

Fattah KA, Lashin A (2016) Investigation of mud density and weighting materials effect on drilling fluid filter cake properties and formation damage. J African Earth Sci 117:345-357. https://doi. org/10.1016/j.jafrearsci.2016.02.003

Gamal H, Elkatatny S, Basfar S, Al-Majed A (2019) Effect of pH on rheological and filtration properties of water-based drilling fluid based on bentonite. Sustain 11:6714. https://doi.org/10.3390/ su11236714

Geng X, Hu X, Jia X (2014) Recirculated aphron-based drilling fluids. J Pet Explor Prod Technol 4:337-342. https://doi.org/10.1007/ s13202-013-0094-6

Haider S, Messaoud-Boureghda MZ, Aknouche H et al (2019) An ecological water-based drilling mud (WBM) with low cost: substitution of polymers by wood wastes. J Pet Explor Prod Technol 9:307-313. https://doi.org/10.1007/s13202-018-0469-9

Hamad BA, He M, Xu M et al (2020) A novel amphoteric polymer as a rheology enhancer and fluid-loss control agent for water-based drilling muds at elevated temperatures. ACS Omega 5:8483-8495. https://doi.org/10.1021/acsomega.9b03774

Hossain ME, Wajheeuddin M (2016) The use of grass as an environmentally friendly additive in water-based drilling fluids. Pet Sci 13:292-303. https://doi.org/10.1007/s12182-016-0083-8

Huang W, Leong YK, Chen T et al (2016) Surface chemistry and rheological properties of API bentonite drilling fluid: $\mathrm{pH}$ effect,

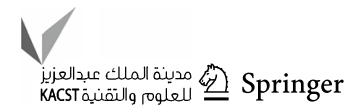


yield stress, zeta potential and ageing behaviour. J Pet Sci Eng 146:561-569. https://doi.org/10.1016/j.petrol.2016.07.016

Idress M, Hasan ML (2020) Investigation of different environmental-friendly waste materials as lost circulation additive in drilling fluids. J Pet Explor Prod Technol 10:233-242. https://doi. org/10.1007/s13202-019-00752-Z

Jung Y, Son YH, Lee JK et al (2011) Rheological behavior of claynanoparticle hybrid-added bentonite suspensions: specific role of hybrid additives on the gelation of clay-based fluids. ACS Appl Mater Interfaces 3:3515-3522. https://doi.org/10.1021/am200 $742 b$

Kekpugile K, Godwin Jacob C (2014) Drilling fluid formulation using cellulose generated from groundnut husk. Int J Adv Res Technol 3:65-71

Khamehchi E, Tabibzadeh S, Alizadeh A (2016) Rheological properties of Aphron based drilling fluids. Pet Explor Dev 43:1076-1081. https://doi.org/10.11698/PED.2016.06.16

Kosynkin DV, Ceriotti G, Wilson KC et al (2012) Graphene oxide as a high-performance fluid-loss-control additive in water-based drilling fluids. ACS Appl Mater Interfaces 4:222-227. https://doi. org/10.1021/am2012799

Kumar S, Thakur A, Kumar N, Husein MM (2020) A novel oil-in-water drilling mud formulated with extracts from Indian mango seed oil. Pet Sci 17:196-210. https://doi.org/10.1007/s12182-019-00371-7

Li FX, Jiang GC, Wang ZK, Cui MR (2014) Drilling fluid from natural vegetable gum. Pet Sci Technol 32:738-744. https://doi. org/10.1080/10916466.2011.605092

Li MC, Wu Q, Song K et al (2018) PH-responsive water-based drilling fluids containing bentonite and chitin nanocrystals. ACS Sustain Chem Eng 6:3783-3795. https://doi.org/10.1021/acssuschem eng.7b04156

Liu T, Jiang G, Zhang P et al (2016) A new low-cost drilling fluid for drilling in natural gas hydrate-bearing sediments. J Nat Gas Sci Eng 33:934-941. https://doi.org/10.1016/j.jngse.2016.06.017

Marques NDN, Garcia CSDN, Madruga LYC et al (2019) Turning industrial waste into a valuable bioproduct: starch from mango kernel derivative to oil industry mango starch derivative in oil industry. J Renew Mater 7:139-152. https://doi.org/10.32604/ jrm.2019.00040

Nasiri M, Ashrafizadeh SN (2010) Novel equation for the prediction of rheological parameters of drilling fluids in an annulus. Ind Eng Chem Res 49:3374-3385. https://doi.org/10.1021/ie9009233
Nasiri M, Jafari I (2016) Investigation of drilling fluid loss and its affecting parameters in one of the Iranian gas fields

Okon AN, Akpabio JU, Tugwell KW (2020) Evaluating the locally sourced materials as fluid loss control additives in water-based drilling fluid. Heliyon 6:e04091. https://doi.org/10.1016/j.heliy on.2020.e04091

Saboori R, Sabbaghi S, Kalantariasl A, Mowla D (2018) Improvement in filtration properties of water-based drilling fluid by nanocarboxymethyl cellulose/polystyrene core-shell nanocomposite. J Pet Explor Prod Technol 8:445-454. https://doi.org/10.1007/s1320 2-018-0432-9

Saboori R, Sabbaghi S, Kalantariasl A (2019) Improvement of rheological, filtration and thermal conductivity of bentonite drilling fluid using copper oxide/polyacrylamide nanocomposite. Powder Technol 353:257-266. https://doi.org/10.1016/j.powtec.2019.05.038

Sarah A, Isehunwa S (2015) Temperature and time-dependent behaviour of a water base mud treated with maize (Zea mays) and cassava (Manihot esculanta) starches. J Sci Res Reports 5:591-597. https://doi.org/10.9734/JSRR/2015/14870

Shettigar RR, Misra NM, Patel K (2018) Cationic surfactant (CTAB) a multipurpose additive in polymer-based drilling fluids. J Pet Explor Prod Technol 8:597-606. https://doi.org/10.1007/s1320 2-017-0357-8

Shuixiang X, Guancheng J, Mian C et al (2011) An environment friendly drilling fluid system. Pet Explor Dev 38:369-378. https ://doi.org/10.1016/S1876-3804(11)60040-2

Vryzas Z, Kelessidis VC (2017) Nano-based drilling fluids: a review. Energies 10:540. https://doi.org/10.3390/en10040540

Yao R, Jiang G, Li W et al (2014) Effect of water-based drilling fluid components on filter cake structure. Powder Technol 262:51-61. https://doi.org/10.1016/j.powtec.2014.04.060

Publisher's Note Springer Nature remains neutral with regard to jurisdictional claims in published maps and institutional affiliations. 